\title{
Numerical Modelling of Headed Bar Joints subjected to Tension
}

\author{
Jean Paul Vellaa, Robert L. Volluma, Andrew Jackson ${ }^{\mathrm{b}}$ \\ aDepartment of Civil and Environmental Engineering, Imperial College London, UK \\ bEngineering Excellence Group, Laing O’Rourke, UK
}

\begin{abstract}
The paper addresses the analysis and design of narrow cast in-situ joints between precast concrete elements in which continuity of reinforcement is achieved through overlapping headed bars. Using headed bars minimises the lap length required within the cast-in-situ joint region. The paper describes a nonlinear finite element model (NLFEM) which was used to simulate a series of tension splice tests carried out by the authors to simulate the tensile zone of a joint loaded in pure flexure. The tests studied the influences of concrete strength, transverse reinforcement, confining shear studs, headed bar spacing and lap length on joint strength. Results show that the NLFEM captures the behaviour of the joint well. Parametric studies are carried out with the validated numerical model to investigate the effects of variables not considered in the tests such as shear stud size, cover and out-of-plane offset of the headed bars. The NLFEM provides otherwise unavailable insights into joint behaviour and is considered suitable for the design of standard joint configurations. Additionally, it can assist the development of design oriented analysis methods.
\end{abstract}

Keywords: Anchors and anchorages, Finite element methods, Floors, Joints, Precast concrete

\section{List of notations}

$\varepsilon_{2} \quad$ Reinforcement strain at end of yield/start of strain hardening

E3 Reinforcement strain at ultimate stress

$\theta \quad$ Angle of a line drawn between the centrelines of opposite heads to a line normal to the headed bars

$v \quad$ Poisson's ratio

$\sigma_{2} \quad$ Reinforcement stress at end of yield/start of strain hardening

$\sigma_{3} \quad$ Reinforcement ultimate stress 


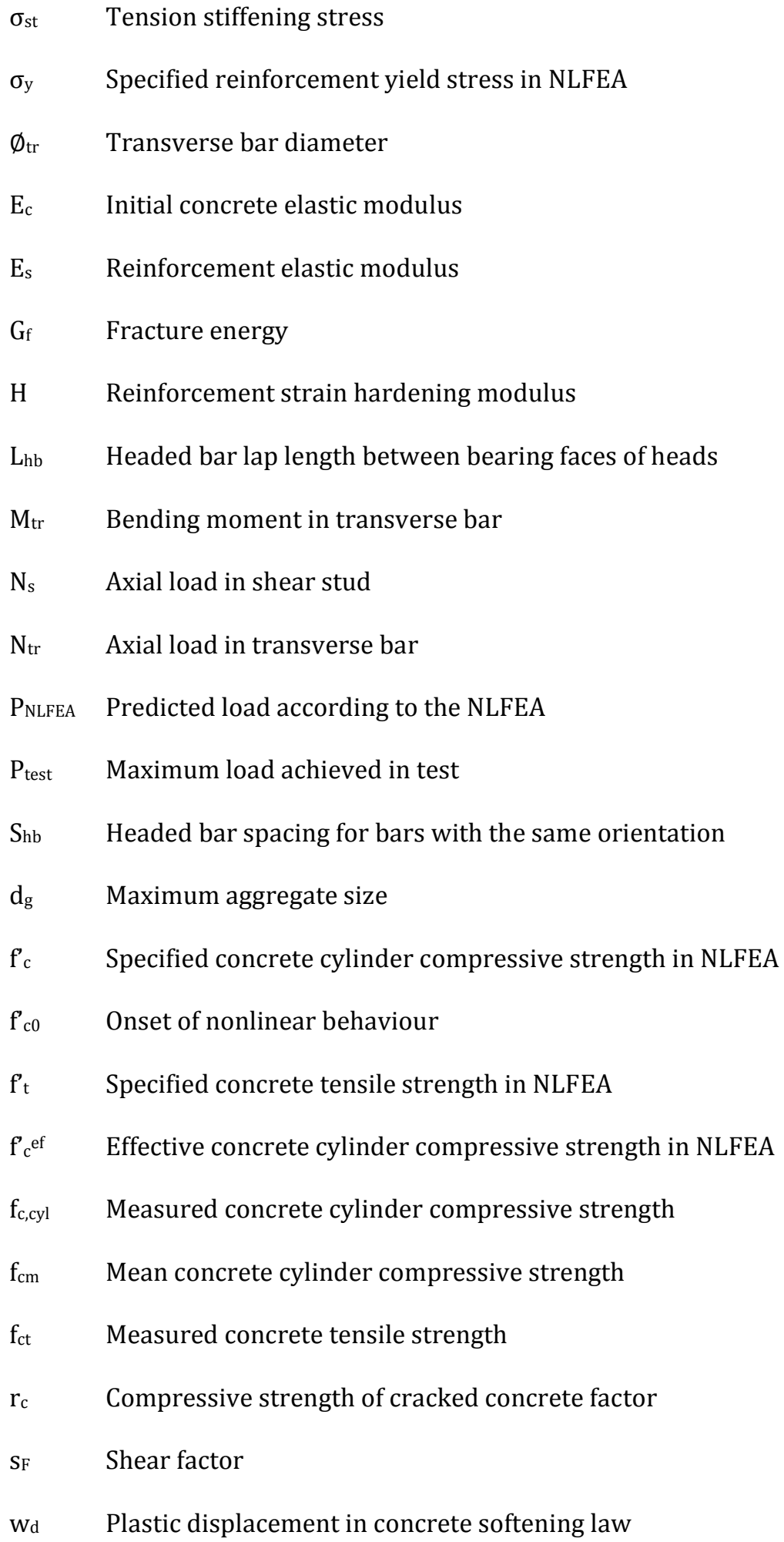




\section{Introduction}

The paper concerns the numerical analysis of narrow cast in-situ joints between precast concrete elements in which continuity of reinforcement is achieved through overlapping headed bars (Figure 1). This type of connection has many practical applications due to the great reduction in required lap length compared with conventional straight reinforcement bars. For example, it is used by Laing O'Rourke (LOR) in their patented E6 floor system to form a continuous concrete floor by connecting precast concrete floor planks within the floor depth.

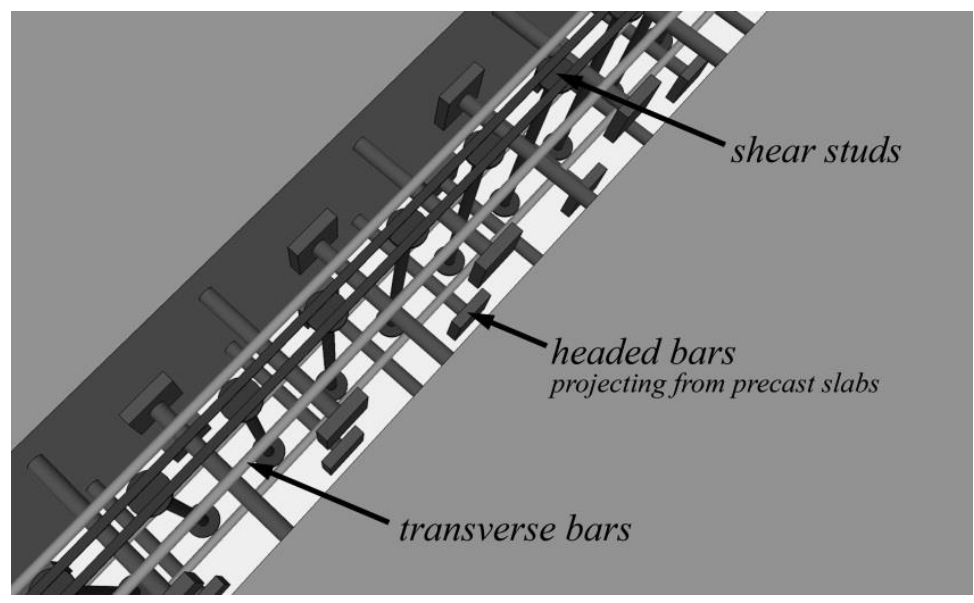

Figure 1: Headed bar joint

A series of three bar tension splice joints (Figure 2) were tested at Imperial College London to determine the influence on strength of joint geometry, concrete strength, transverse reinforcement and confining shear studs of the type used in stud rails for punching shear reinforcement (Ferreira et al., 2014). The results of this research are generic and apply to headed bar tension laps which can be used in closure pours as well as joints between precast elements. A lap length of $100 \mathrm{~mm}$ in $28 \mathrm{MPa}$ concrete was found to be sufficient to develop the full strength of $25 \mathrm{~mm}$ diameter high strength headed bars compared with around a metre for straight bars. Currently, LOR use a STM like that shown in Figure 3 for the design of headed bar tension splices. The strength of the inclined struts in the STM is assumed to be increased by confinement when shear studs are present. Analysis of splice joints tested by the authors shows that the STM gives overly conservative estimates of joint resistance, when concrete failure governs, without always capturing the observed failure mechanism (Vella et al., 2017a). 

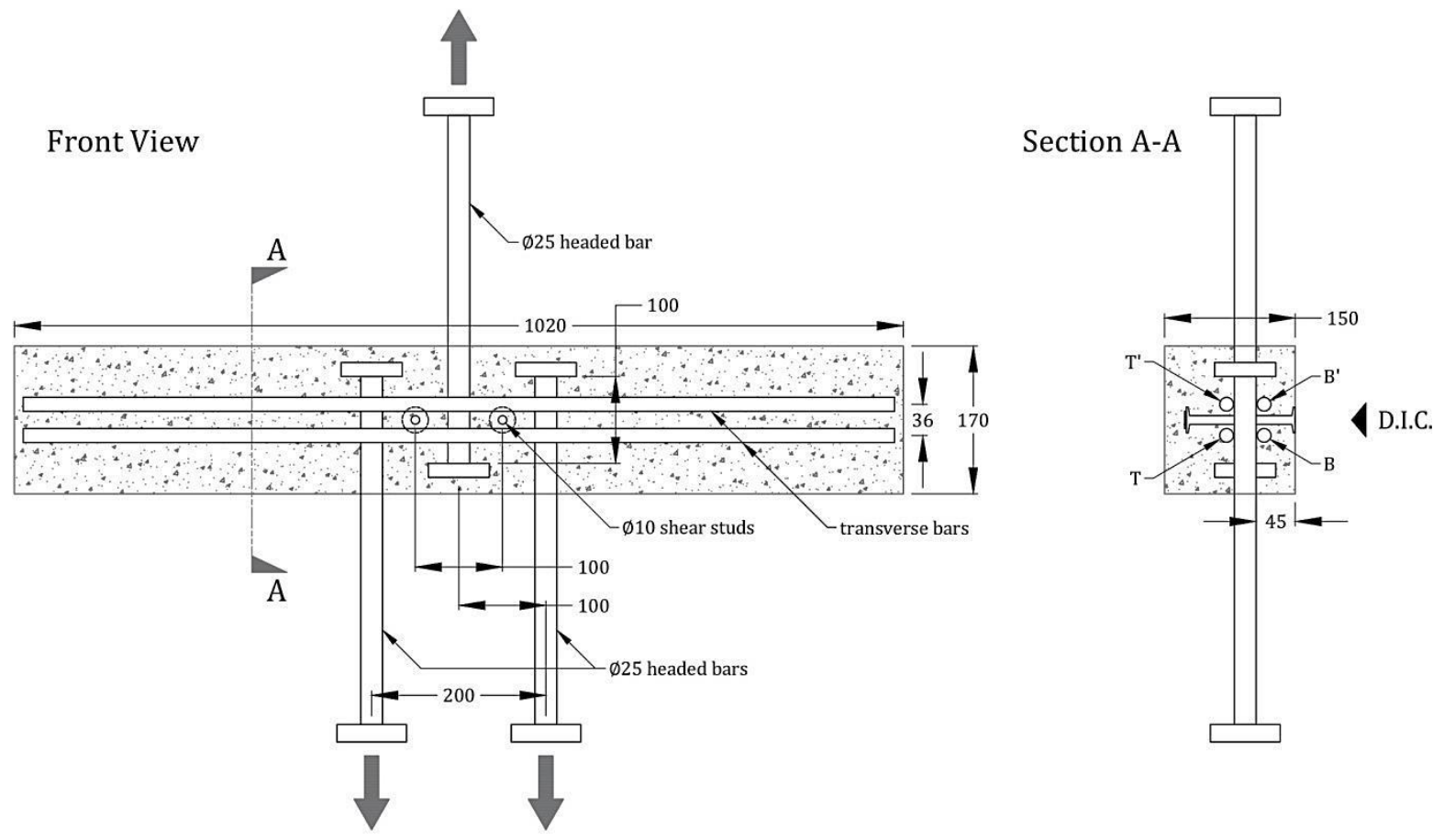

Figure 2: Typical test specimen

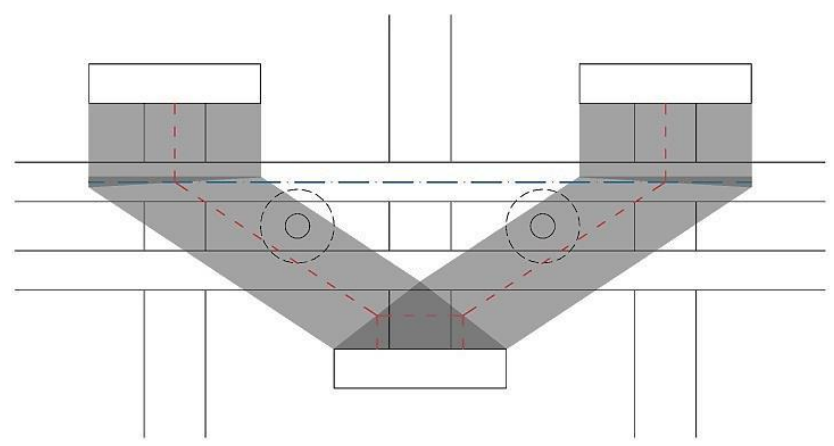

Figure 3: STM schematic for three bar arrangement

Headed bar tension splices have been tested by several researchers (Chun, 2015, Li et al., 2010a, Li et al., 2010b, Thompson et al., 2006, Thompson et al., 2003) but there appears to be a complete lack of published literature on the nonlinear finite element analysis (NLFEA) of such connections. Numerical modelling of headed bar joints is challenging due to the highly complex three dimensional stress distribution within the joint which makes 2D analysis inappropriate. Numerical analysis was carried out in this research using the commercially available package ATENA-GiD (Cervenka et al., 2014). The resulting model is shown to capture the observed joint behaviour well including reinforcement bar strains and crack patterns. The NLFEA model is used to carry out parametric studies to investigate the influence of variables not considered in the laboratory tests. 


\section{Research Significance}

The results presented in this paper show that headed bar tension splice joints are very efficient with strength dependent on reinforcement detailing within the joint and concrete strength. The described NLFEA captures key aspects of joint behaviour including strength and deformation and is considered suitable for the design of standard joint configurations.

\section{Laboratory Tests}

Twenty one of the twenty seven specimens tested had the standard geometrical arrangement shown in Figure 2. The specimens were intended to simulate the tension zone of a flexural splice. In the standard arrangement, reinforcement bars in the precast unit on each side of the joint are spaced at $200 \mathrm{~mm}$ and the lap length between the inside face of the heads is $100 \mathrm{~mm}$. The variables tested were concrete strength, transverse bar size and arrangement and the presence or absence of shear studs. The remaining six tests investigated the influence of varying the headed bar spacing and lap length. The headed bars were $25 \mathrm{~mm}$ in diameter with standard $70 \times 70 \times 16 \mathrm{~mm}$ friction welded square heads. Their length was $400 \mathrm{~mm}$, measured between the inside faces of the heads. Where present, two $10 \mathrm{~mm}$ diameter $125 \mathrm{~mm}$ long shear studs were placed at the positions shown in Figure 2. The concrete strength was varied in the tests with a view to determining the critical concrete strength at which headed bar yield precedes concrete failure. The majority of specimens were designed to fail prior to headed bar yield in order to better observe the influence of transverse bar arrangement and shear studs on joint performance. Details of the tested specimens, which are divided into five groups, are summarised in Table 1, with the test ID describing the specimens as follows:

For example, G4-39-2H20:TT'-S-100-250:

“G4" - Test group

“39" - Measured concrete cylinder strength at time of testing

“ $2 \mathrm{H} 20$ " - Number and diameter of transverse bars

“TT" - Position of transverse bars as indicated in Figure 3

"S" - - Shear studs included

“ 100 " - Lap length of headed bars

“ $250 "$ - Spacing of headed bars 


\begin{tabular}{|c|c|c|c|c|c|c|c|c|c|}
\hline Test ID & $\begin{array}{c}\mathrm{f}_{\mathrm{c}, \mathrm{cyl}} \\
(\mathrm{MPa})\end{array}$ & $\begin{array}{c}\mathrm{f}_{\mathrm{ct}} \\
(\mathrm{MPa})\end{array}$ & $\begin{array}{c}\emptyset_{\mathrm{tr}} \\
(\mathrm{mm})\end{array}$ & $\begin{array}{c}\text { Transverse } \\
\text { Bar } \\
\text { Positions }\end{array}$ & $\begin{array}{c}S_{\mathrm{hb}} \\
(\mathrm{mm})\end{array}$ & $\begin{array}{c}\text { Lhb } \\
(\mathrm{mm})\end{array}$ & $\begin{array}{c}P_{\text {test }} \\
(k N) \\
\text { \{failure } \\
\text { mode }\end{array}$ & $\begin{array}{c}\text { P }_{\text {NLFEA }} \\
(k N) \\
\text { failure } \\
\text { mode }\end{array}$ & $\frac{\mathrm{P}_{\text {NLFEA }}}{P_{\text {test }}}$ \\
\hline G1-26-2H16:TT-S-100-200 & 25.6 & 2.38 & 16 & T T' & 200 & 100 & $149\{\mathrm{~J}\}$ & $174\{\mathrm{~J}\}$ & 1.17 \\
\hline G1-40-2H16:TT-S-100-200 & 40.4 & 3.60 & 16 & $\mathrm{~T} \mathrm{~T}^{\prime}$ & 200 & 100 & $232\{\mathrm{~J}\}$ & $217\{\mathrm{~J}\}$ & 0.94 \\
\hline G1-54-2H16:TT-S-100-200 & 54.3 & 4.57 & 16 & $\mathrm{~T} \mathrm{~T}^{\prime}$ & 200 & 100 & $259\{\mathrm{~J}\}$ & $247\{\mathrm{~J}\}$ & 0.95 \\
\hline G1-26-2H20:TT-S-100-200 & 25.6 & 2.38 & 20 & $\mathrm{~T} \mathrm{~T}^{\prime}$ & 200 & 100 & $154\{\mathrm{~J}\}$ & $187\{J\}$ & 1.21 \\
\hline G1-40-2H20:TT-S-100-200 & 40.4 & 3.60 & 20 & $\mathrm{~T} \mathrm{~T}^{\prime}$ & 200 & 100 & $242\{\mathrm{~J}\}$ & $232\{J\}$ & 0.96 \\
\hline G1-54-2H20:TT-S-100-200 & 54.3 & 4.57 & 20 & $\mathrm{~T} \mathrm{~T}^{\prime}$ & 200 & 100 & $286\{\mathrm{H}\}$ & $263\{\mathrm{H}\}$ & 0.92 \\
\hline G1-48-2H25:TT'-S-100-200 & 48.0 & 4.04 & 25 & $\mathrm{~T} \mathrm{~T}^{\prime}$ & 200 & 100 & $260\{\mathrm{~J}\}$ & $265\{\mathrm{H}\}$ & 1.02 \\
\hline G2-26-2H16:TT-100-200 & 25.6 & 2.38 & 16 & $\mathrm{~T} \mathrm{~T}^{\prime}$ & 200 & 100 & $124\{\mathrm{~J}\}$ & $147\{\mathrm{~J}\}$ & 1.19 \\
\hline G2-40-2H16:TT-100-200 & 40.4 & 3.60 & 16 & $\mathrm{~T} \mathrm{~T}^{\prime}$ & 200 & 100 & $181\{\mathrm{~J}\}$ & $196\{J\}$ & 1.08 \\
\hline G2-54-2H16:TT-100-200 & 54.3 & 4.57 & 16 & $\mathrm{~T} \mathrm{~T}^{\prime}$ & 200 & 100 & $220\{\mathrm{~J}\}$ & $228\{J\}$ & 1.03 \\
\hline G2-26-2H20:TT-100-200 & 25.6 & 2.38 & 20 & $\mathrm{~T} \mathrm{~T}^{\prime}$ & 200 & 100 & $133\{\mathrm{~J}\}$ & $159\{J\}$ & 1.19 \\
\hline G2-40-2H20:TT'-100-200 & 40.4 & 3.60 & 20 & $\mathrm{~T} \mathrm{~T}^{\prime}$ & 200 & 100 & $207\{\mathrm{~J}\}$ & $212\{\mathrm{~J}\}$ & 1.03 \\
\hline G2-54-2H20:TT-100-200 & 54.3 & 4.57 & 20 & $\mathrm{~T} \mathrm{~T}^{\prime}$ & 200 & 100 & $257\{\mathrm{~J}\}$ & $254\{J\}$ & 0.99 \\
\hline G2-48-2H25:TT-100-200 & 48.0 & 4.04 & 25 & $\mathrm{~T} \mathrm{~T}^{\prime}$ & 200 & 100 & $209\{\mathrm{~J}\}$ & $253\{J\}$ & 1.21 \\
\hline G3-28-2H20:T'B'-S-100-200 & 27.7 & 2.65 & 20 & $\mathrm{~T}^{\prime} \mathrm{B}^{\prime}$ & 200 & 100 & $236\{\mathrm{~J}\}$ & $218\{\mathrm{~J}\}$ & 0.92 \\
\hline G3-28-4H16:TT'BB'S-100-200 & 27.7 & 2.65 & 16 & T T' B B' & 200 & 100 & $264\{\mathrm{H}\}$ & $239\{\mathrm{~J}\}$ & 0.91 \\
\hline G3-28-4H20:TT'BB'-S-100-200 & 27.7 & 2.65 & 20 & T T' B B' & 200 & 100 & $312\{\mathrm{H}\}$ & $274\{\mathrm{H}\}$ & 0.88 \\
\hline G3-46-2H20:T'B'-S-100-200 & 46.1 & 3.80 & 20 & $\mathrm{~T}^{\prime} \mathrm{B}^{\prime}$ & 200 & 100 & $316\{\mathrm{H}\}$ & $288\{\mathrm{H}\}$ & 0.91 \\
\hline G3-46-4H16:TT'BB'-S-100-200 & 46.1 & 3.80 & 16 & T T' B B' & 200 & 100 & $318\{\mathrm{H}\}$ & $293\{\mathrm{H}\}$ & 0.92 \\
\hline G3-46-2H16:T'B'-S-100-200 & 46.1 & 3.80 & 16 & $\mathrm{~T}^{\prime} \mathrm{B}^{\prime}$ & 200 & 100 & $290\{\mathrm{H}\}$ & $257\{J\}$ & 0.89 \\
\hline G3-48-1H25:T-S-100-200 & 48.0 & 4.04 & 25 & $\mathrm{~T}^{\prime}$ & 200 & 100 & $243\{\mathrm{~J}\}$ & $243\{J\}$ & 1.00 \\
\hline G4-39-2H20:TT-S-100-150 & 39.2 & 3.36 & 20 & T T' & 150 & 100 & $288\{\mathrm{H}\}$ & $275\{\mathrm{H}\}$ & 0.95 \\
\hline G4-39-2H20:TT-S-100-250 & 39.2 & 3.36 & 20 & $\mathrm{~T} \mathrm{~T}^{\prime}$ & 250 & 100 & $190\{\mathrm{~J}\}$ & $155\{J\}$ & 0.81 \\
\hline G4-39-2H20:TT-S-100-300 & 39.2 & 3.36 & 20 & $\mathrm{~T} \mathrm{~T}^{\prime}$ & 300 & 100 & $130\{\mathrm{~J}\}$ & $111\{J\}$ & 0.85 \\
\hline G5-25-2H20:TT-S-75-200 & 24.8 & 2.13 & 20 & $\mathrm{~T} \mathrm{~T}^{\prime}$ & 200 & 75 & $117\{\mathrm{~J}\}$ & $132\{\mathrm{~J}\}$ & 1.13 \\
\hline G5-25-2H20:TT-S-150-200 & 24.8 & 2.13 & 20 & $\mathrm{~T} \mathrm{~T}^{\prime}$ & 200 & 150 & $213\{\mathrm{~J}\}$ & $209\{J\}$ & 0.98 \\
\hline G5-25-2H20:TT-S-200-200 & 24.8 & 2.13 & 20 & $\mathrm{~T} \mathrm{~T}^{\prime}$ & 200 & 200 & $261\{\mathrm{~J}\}$ & $219\{J\}$ & 0.84 \\
\hline
\end{tabular}


Groups 1 and 2 were identical apart from the omission of shear studs in group 2. The specimens were designed to investigate the influence on joint strength of concrete strength and transverse bar diameter when positioned in the $\mathrm{T}$ and $\mathrm{T}^{\prime}$ locations (see Figure 2). Groups 3 to 5 respectively varied the spatial arrangement of transverse bars, spacing of headed bars and lap length of headed bars. In group 5, the centrelines of transverse bars were positioned $32 \mathrm{~mm}$ from the inside face of the heads as shown in Figure 2. Consequently, the spacing of the transverse bars varied with the lap length.

The load and platen-to-platen displacement were recorded from the test rig, and several strain gauges were fixed to the reinforcement inside the concrete. Additionally, digital image correlation (DIC) was used to monitor cracking in the face parallel to the plane of the headed bars with minimum cover (see Figure 2 Section A-A).

\section{Numerical Modelling in ATENA-GiD}

Numerical modelling was carried out with the nonlinear finite element package ATENA-GiD (Cervenka et al., 2014). GiD was used as a pre-processor for geometrical modelling and specifying input data. The analysis was run using ATENA Studio (Benes et al., 2015), in which post-processing was also carried out.

\section{Geometry and Finite Element Mesh}

Taking advantage of symmetry, only half of the test specimen was modelled (Figure 4). Initial studies showed that the proper behaviour of the joint could only be captured by considering the bending and shear stiffness of the transverse and headed reinforcement bars. Therefore, these bars were modelled with brick elements since the 1D truss elements in ATENA only have axial stiffness (Pryl and Cervenka, 2014). For simplicity, the main headed and transverse bars were modelled with square cross-sections having the same second moment of area as the provided circular bars. The cross-sectional area of the equivalent square bars was around $2 \%$ less than the actual area. In order to represent the cross-section of reinforcement bars with at least four elements, the element side length was locally adjusted as shown in Figure 4a. The end of the loaded bar was extended to create a stiff loading plate to avoid issues arising from stress concentrations. The loading plate was modelled with linear elastic 4-noded "CCIsoTetra" isoparametric tetrahedral elements. To simplify the model, the heads of shear studs were modelled entirely outside the concrete and as square (Figure $4 \mathrm{~b}$ ) with similar surface area to the actual heads. The shaft of the shear stud was modelled with the linear embedded truss element, "CCIsoTruss". 


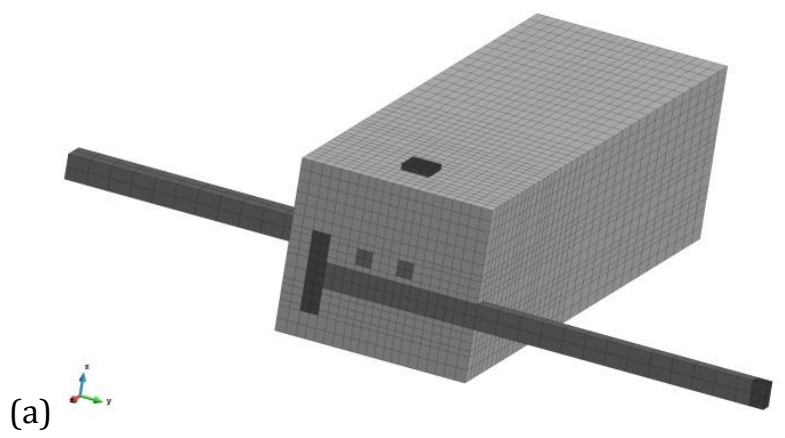

(b) $\stackrel{\dot{L}}{\dot{x}}$
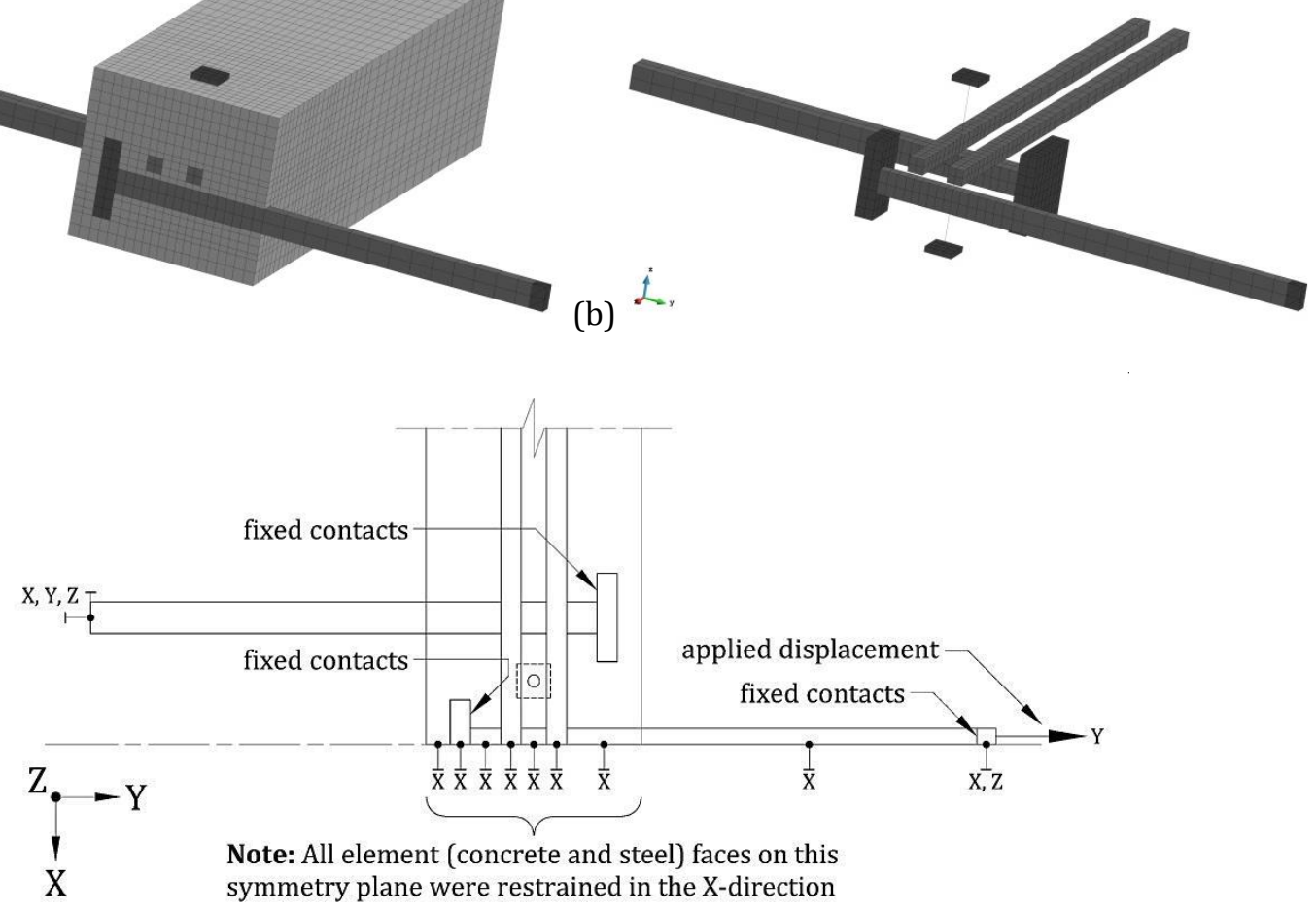

Figure 4: a) Full FE model, b) FE steel components only, c) Boundary conditions

To simplify the model and reduce computational requirements, nodes at the interfaces between elements representing the bars and concrete are shared, meaning that perfect bond is assumed between reinforcement and concrete. Pryl and Cervenka (2014) state that this is realistic for ribbed bars, provided the mesh is sufficiently refined, since the concrete elements surrounding the reinforcement crack with increasing load, thereby reducing the stiffening effect resulting from perfect connectivity. The assumption of perfect bond is also in accordance with guidelines published by the Dutch Ministry for Infrastructure and the Environment (Hendriks et al., 2012). For consistency, the shear stud was also considered to be perfectly bonded to the concrete.

Heads of bars are considered to be connected to the concrete only on the bearing face, as shown in Figure 4c. Fixed contacts were defined at these surfaces by introducing master-slave constraints, linking the surfaces of the adjacent steel and concrete elements at that location. No connection was made between the concrete and other head faces. Fixed contacts were required at the interface between the loading plate and bar since different element types were used. End displacements were monitored at the end of the loaded bar, on the inside face of the loading plate. 


\section{Boundary Conditions}

Figure 4c shows the boundary conditions applied to the finite element model. The end of the supporting bar was constrained in all directions, the loading plate was constrained in the $\mathrm{x}$ and $\mathrm{z}$-directions and the plane of symmetry was constrained in the x-direction. A prescribed displacement of $0.02 \mathrm{~mm}$ per load step was applied in the y-direction to the end of the loaded bar. The Newton-Raphson iteration scheme was used for solving the nonlinear equations at each load step.

\section{Material Constitutive Models}

Concrete was modelled with the "CC3DNonLinCementitious2" model available in ATENA which is a fracture-plastic model, combining constitutive models for tensile and compressive behaviour (Figure 5a). The failure surface of Menetrey and Willam (1995) is used for concrete crushing in CC3DNonLinCementitious2. The hardening-softening law is based on the uniaxial compressive test. It is assumed that compression failure is localized in a plane normal to the direction of compressive principal stress. A linear strain softening branch is adopted with the end point at zero stress defined by a plastic displacement $w_{d}$ (Figure $5 \mathrm{~b}$ ). This approach indirectly defines the energy needed for generation of a unit area of the failure plane. The default value of $w_{d}=0.5 \mathrm{~mm}$ for normal concrete is based on the experimental work of Van Mier (1986). The compressive strength of concrete is reduced in accordance with the recommendations of Vecchio and Collins (1986) when cracking occurs in the perpendicular direction. The maximum strength reduction factor is limited to a multiple $r_{c}$ of the concrete uniaxial compressive strength.

The tensile fracture model in ATENA employs the smeared crack approach. The fixed crack option was adopted in the present analyses since it captured the observed response more realistically than the rotating crack option. A variable shear retention factor derived by Kolmar, as described by Cervenka et al. (2013) was used to account for the reduction of shear stiffness resulting from crack opening as recommended by Hendriks et al. (2012). Table 2 lists the concrete material properties used in the analyses of the tested specimens which were chosen on the basis of sensitivity studies as described in the next section. The concrete elastic modulus and fracture energy were calculated in accordance with fib (1999) and fib MC2010 (fib, 2013) respectively. 


\begin{tabular}{lll}
\hline Parameter & Function & \\
\hline Cylinder strength & $f_{c}^{\prime}=$ Measured (given in Table 1) & \\
Tensile strength & $f_{t}^{\prime}=$ Measured (given in Table 1) & \\
Initial elastic modulus & $E_{c}=2.15 \mathrm{e}+4\left(f_{c m} / 10\right)^{1 / 3}$ & (Default value) \\
Poisson's ratio & $v=0.2$ & (Default value) \\
Compression softening & $w_{d}=-1.8 \mathrm{~mm}$ & \\
Compressive strength in cracked concrete & $r_{c}=0.3$ & \\
Tension stiffening stress & $\sigma_{s t}=0$ & (Default value) \\
Fracture energy & $G_{f}=73 f_{c m}^{0.18}$ & (Default value) \\
Onset of nonlinear behaviour & $f_{c 0}=2 f_{t}^{t}$ & (Default function) \\
Shear factor & $S_{F}=20$ & (Default value) \\
Maximum aggregate size & $\mathrm{d}_{\mathrm{g}}=10 \mathrm{~mm}$ & \\
\hline
\end{tabular}

Table 2: Concrete constitutive model parameters

(a)

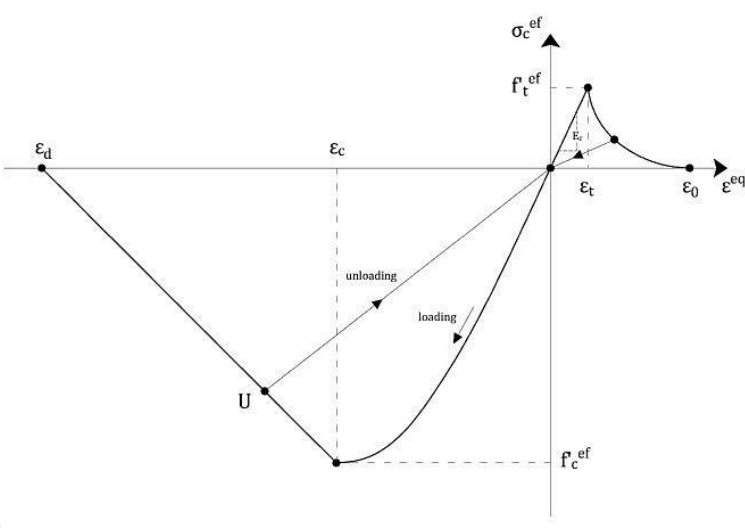

(b)

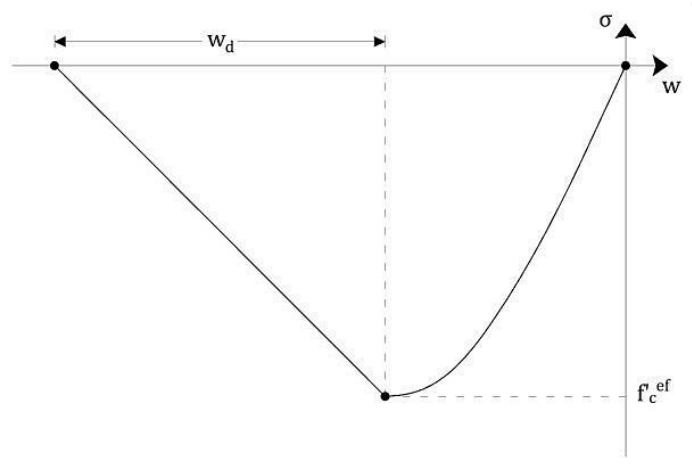

(c)

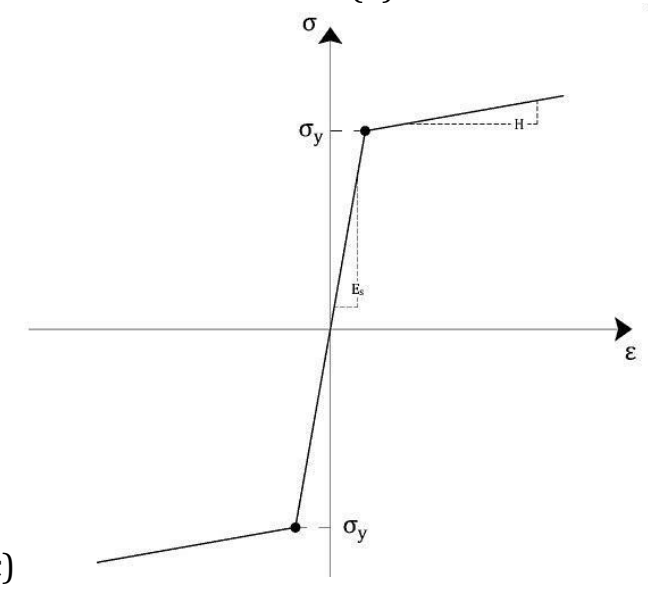

Figure 5: a) ATENA concrete uniaxial stress-strain law, b) concrete softening in compression, c) steel stressstrain law

Steel elements, including; the transverse and headed bars, and the heads of the headed bars and stud, were modelled using the "CC3DBiLinearSteelVonMises" material model. The stress-strain law is bilinear with an initial elastic branch, followed by a plastic hardening branch (Figure $5 c$ ) defined by the yield strength $\left(\sigma_{y}\right)$, elastic modulus $\left(E_{s}\right)$ and hardening modulus $(H)$. The Poisson's ratio $(v)$ also needs to be specified. The perfectly elastic material "CC3DElastIsotropic" was used for the elastic elements provided 
at the end of the loaded headed bar. Table 3 lists the reinforcement properties used in the NLFEA which were derived from coupon tests.

\begin{tabular}{ccccc}
\hline Component & $\sigma_{y}(\mathrm{MPa})$ & $E_{s}(\mathrm{GPa})$ & $H(\mathrm{MPa})$ & $v$ \\
\hline Bar Heads & 355 & 200 & $1.0 \mathrm{e}+4$ & 0.3 \\
Headed Bars & 530 & 197 & $1.0 \mathrm{e}+4$ & 0.3 \\
16mm Transverse Bars & 536 & 206 & 0 & 0.3 \\
20mm Transverse Bars & 539 & 211 & 0 & 0.3 \\
25mm Transverse Bars & 552 & 185 & 0 & 0.3 \\
Loading Plate & - & $2.0 \mathrm{e}+4$ & - & 0.05 \\
\hline
\end{tabular}

Table 3: ATENA steel material properties

The shear stud was modelled as "CCReinforcement" using a trilinear stress strain relationship. The initial elastic response is defined by the Young's modulus and yield stress, while the next two linear parts are defined by specifying the measured stress and strain at the end of each segment. The values used in these analyses are presented in Table 4.

\begin{tabular}{cccccc}
\hline$E_{s}(\mathrm{GPa})$ & $\sigma_{y}(\mathrm{MPa})$ & $\varepsilon_{2}$ & $\sigma_{2}(\mathrm{MPa})$ & $\varepsilon_{3}$ & $\sigma_{3}(\mathrm{MPa})$ \\
\hline 213 & 553 & 0.031 & 553 & 0.07 & 628 \\
\hline
\end{tabular}

Table 4: ATENA shear stud material properties

\section{Sensitivity Studies}

Sensitivity studies were carried out to inform the final choice of mesh size, element type and concrete material properties. Specimen G1-26-2H20:TT'-S-100-200 was chosen as the baseline model. Linear 8noded hexahedral elements were used in the baseline model for concrete, headed bars and transverse reinforcement. The maximum element side length in the baseline model was limited to $9 \mathrm{~mm}$ within the central region of the joint. Larger elements were used away from the headed bars, whilst ensuring that the ratio of longest to shortest element side did not exceed two. Baseline concrete material parameters were automatically generated with ATENA-GiD considering a mean safety format for a concrete strength of $25 \mathrm{MPa}$. One parameter was varied at a time leaving the other parameters unchanged. The model predictions were found to be most sensitive to the mesh size and element order, the plastic displacement $w_{d}$, and the limiting cracked concrete compressive strength reduction factor $r_{c}$. Results are only presented here for $w_{d}$ and $r_{c}$ with default values used for all other material properties as shown in Table 2. The observed sensitivity to $w_{d}$ and $r_{\mathrm{c}}$ is consistent with previous studies where adopted parameters varied significantly from default values (Hegger et al., 2004, Costa et al., 2015). The presented load- 
displacement plots include a load-displacement curve for bare bars which was derived by adding the displacement of a fully loaded bar to that of the same bar with half the applied load.

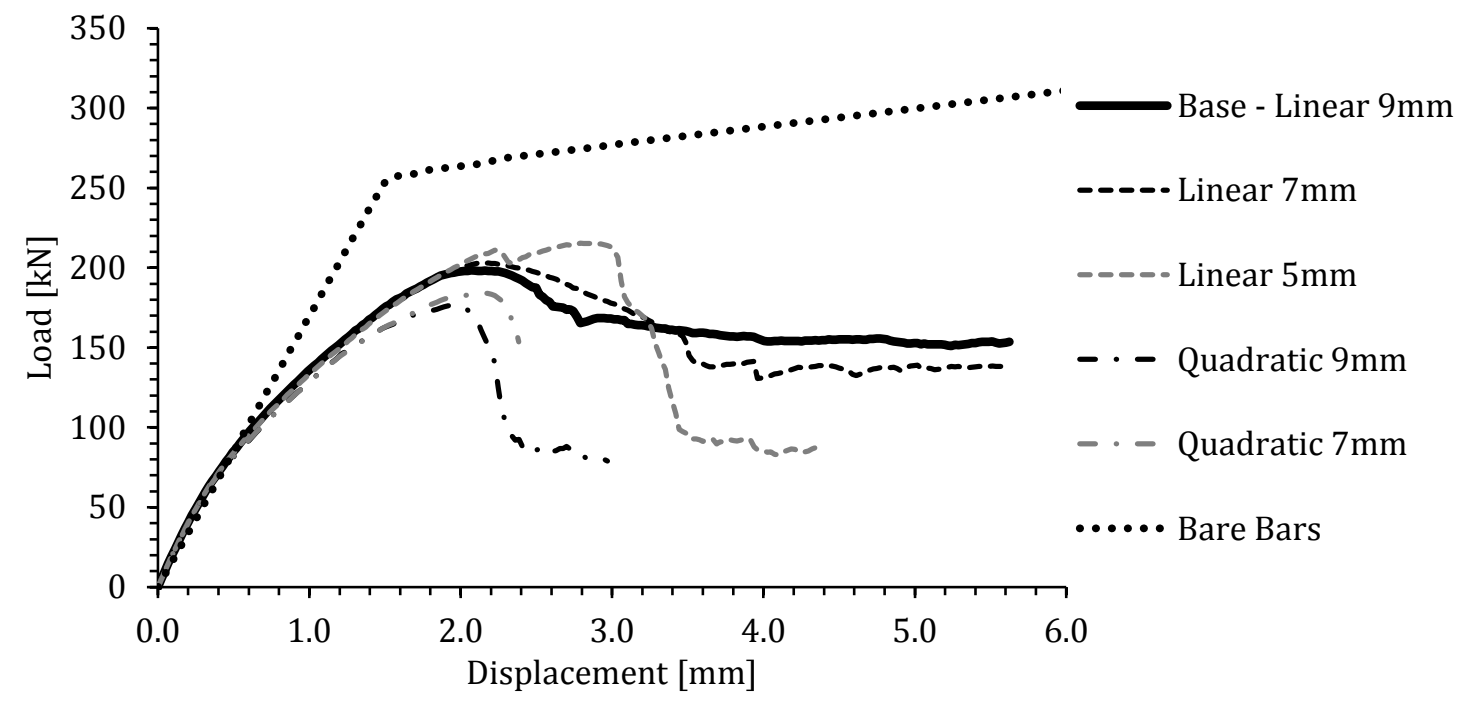

(a)

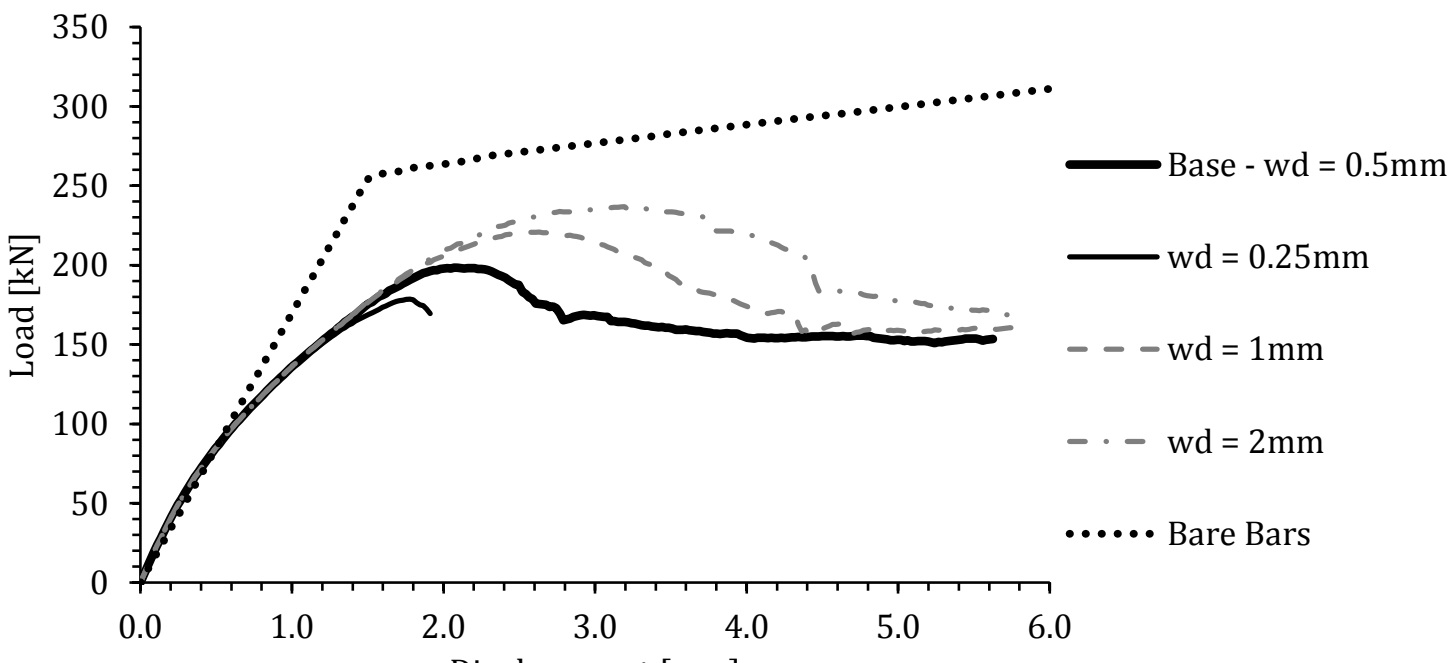

(b)

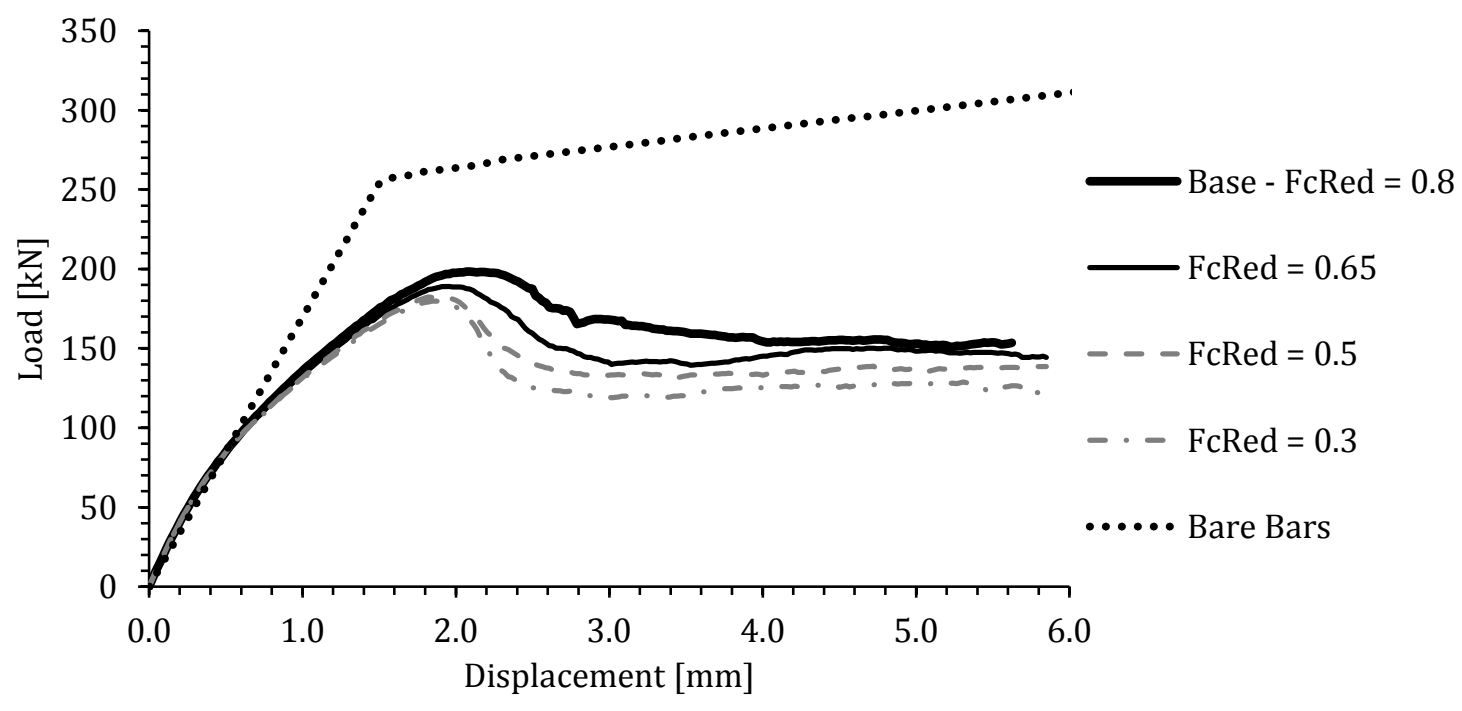

Figure 6: Sensitivity to a) element size and order, b) compression softening law, c) compressive strength reduction due to cracking 


\section{Mesh Size and Order}

The baseline model with linear 8-noded hexahedral elements included around 16,000 nodes. Two more refined models were generated with linear elements having maximum element sizes of $7 \mathrm{~mm}$ and $5 \mathrm{~mm}$, resulting in around 34,000 and 89,000 nodes respectively. Two additional models were analysed using quadratic elements, with 27 gauss points, one with $9 \mathrm{~mm}$ maximum element size, producing approximately 60,000 nodes, and the other with a more refined maximum element size of $7 \mathrm{~mm}$ producing around 122,000 nodes. Figure 6 a shows that the initial load-displacement stiffness is similar for all models but the stiffness decreases more rapidly as the ultimate load is approached for models with higher order elements. For both linear and quadratic elements, refining the mesh slightly increases the ultimate load. The linear element model with the finest mesh exhibits a more brittle response than the other two linear models, whose response is very similar. Models with quadratic elements achieve approximately $10 \%$ lower peak loads and a more brittle post-peak behaviour than the corresponding linear element models.

\section{Compression softening law}

The default value $w_{d}=0.5 \mathrm{~mm}$ was used in the baseline model. Subsequently, models with $w_{d}=0.25 \mathrm{~mm}$, $1 \mathrm{~mm}$ and $2 \mathrm{~mm}$ were analysed. The peak load increases with increasing $w_{d}$, with the baseline resistance increased by around $25 \%$ for $w_{d}=2 \mathrm{~mm}$ (Figure $6 \mathrm{~b}$ ). The post-peak response becomes less brittle as $w_{d}$ is increased.

\section{Compressive strength of cracked concrete}

The suggested maximum compressive strength reduction factor after cracking in the perpendicular direction of $r_{c}=0.8$ was used in the baseline model. Reducing $r_{c}$ to 0.65 slightly decreased the failure load and resulted in a slightly more brittle post-peak response (Figure 6c). Further reductions to $r_{c}=0.5$ and $r_{c}$ $=0.3$, had minimal effect on the peak load capacity but slightly reduced the post-peak residual strength.

\section{Validation of Model with Test Results}

Following the sensitivity studies described above and analyses of selected test specimens, quadratic 20noded hexahedral elements were adopted in the final FEM, as recommended by Hendriks et al. (2012). The maximum element size was $9 \mathrm{~mm}$ in the central region of the joint. The adopted concrete material 
properties are shown in Table 2 in which $w_{d}$ and $r_{c}$ were chosen to give a best fit to the test data. Table 1 lists the resulting joint capacities obtained for the tested specimens.

Failure modes are classified in Table 1 as Joint (J) where concrete failure occurred before or at headed bar yield and Headed bar $(\mathrm{H})$ when extensive yield of the headed bar occurred prior to eventual concrete failure. The data from Table 1 is illustrated in Figure 7, where results are sorted in ascending order according to the maximum load achieved in the tests. Overall, the numerical predictions closely follow the experimental results. Strengths are marginally underestimated for joints with capacities close to the yield strength of the headed bar, which are of most practical concern, but tend to be overestimated at the lowest concrete strength of around $25 \mathrm{MPa}$. The ratio of predicted to measured strength has a mean of 0.99 , standard deviation of 0.118 and coefficient of variation of 0.119 . Three typical test specimens are discussed further below to illustrate the validation of the NLFEA model; G1-26-2H16:TT'-S-100-200, G254-2H20:TT'-S-100-200 and G3-46-2H20:T'B'-S-100-200.

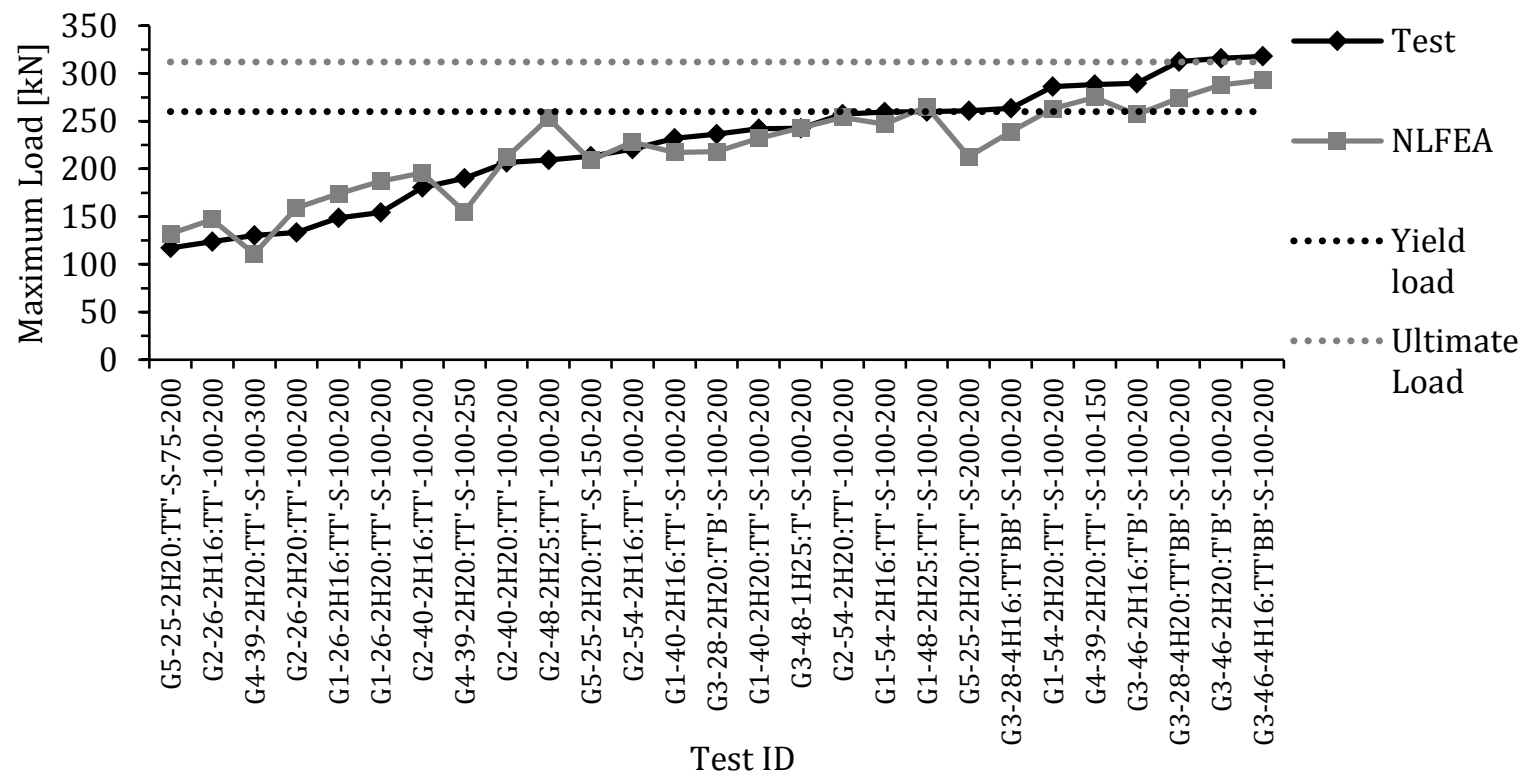

Figure 7: Comparison between test results and unfactored NLFEA predictions

\section{Load-Displacement Response}

Figure 8 shows measured and predicted load-displacement plots for the three tests mentioned above. Displacements are measured between the ends of the supporting and loaded headed bars. The measured displacements were obtained from platen to platen displacements by subtracting the deformation of the clamped heads outside the concrete which was determined from tests on bare bars.

The initial stiffness of the specimens is generally well captured as is the predicted failure mode. The NLFEA over-predicts the failure load of test G1-26-2H16:TT'-S-100-200 by 17\%, but shows a similar post- 
peak response. The peak load for specimen G2-54-2H20:TT'-S-100-200 is well predicted, and the brittle failure is relatively well captured. Specimen G3-46-2H20:T'B'-S-100-200 continued well into the strain hardening region, reaching the ultimate headed bar capacity of $316 \mathrm{kN}$ at a displacement of approximately $36 \mathrm{~mm}$. The NLFEA captures the failure mode of headed bar yield, occurring just outside of the concrete, but the predicted ultimate load is $9 \%$ less than measured.

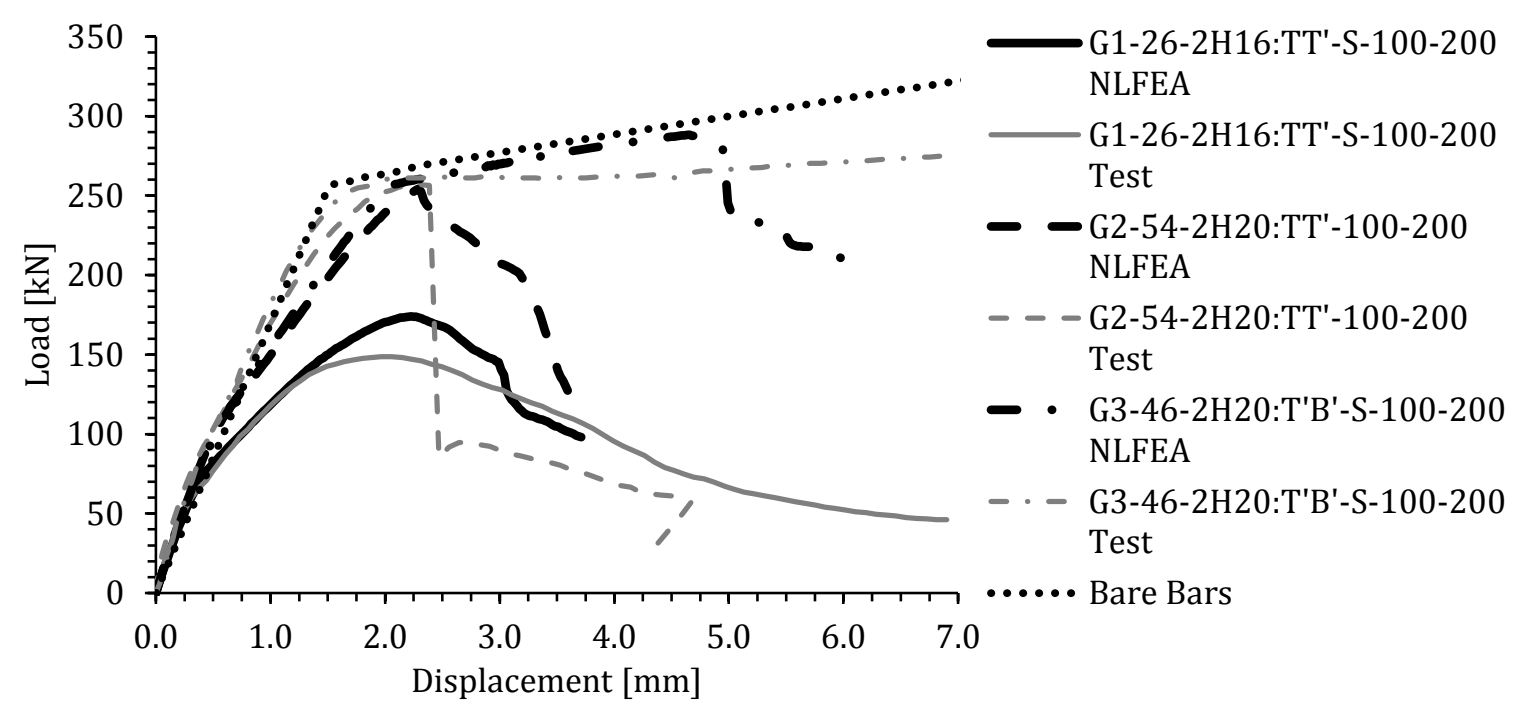

Figure 8: Load-displacement response comparison

(a)

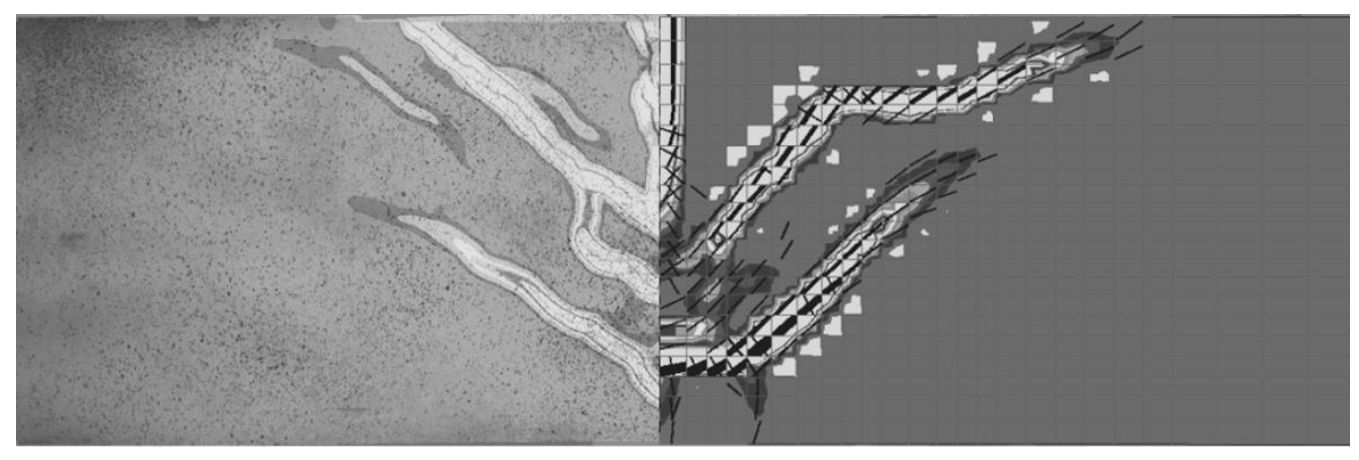

(b)

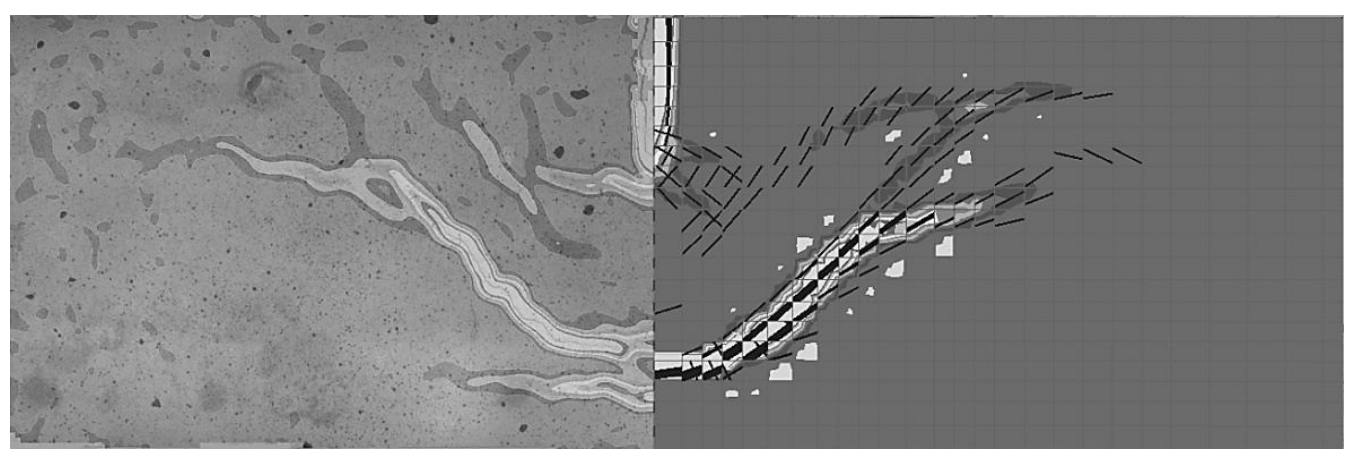

Figure 9: Test (left) and NLFEA (right) crack pattern and principal surface tensile strain comparison: a) G1-262H16:TT'-S-100-200, b) G3-46-2H20T'B'-S-100-200 


\section{Crack Patterns}

In order to further validate the numerical model, Figure 9 compares predicted crack patterns at failure for specimens G1-26-2H16:TT'-S-100-200 and G3-46-2H20:T'B'-S-100-200 with those recorded with DIC. Specimen G2-54-2H20:TT'-S-100-200 is not shown since its crack pattern is very similar to that of G1-262H16:TT'-S-100-200. The crack pattern in G3-46-2H20:T'B'-S-100-200 is shown at the headed bar yield load. The crack formation is captured well in the numerical model with almost exact correspondence between the measured and predicted length of the vertical crack along the central headed bar. Additionally, the NLFEA closely captures the observed trajectories of the diagonal cracks in both specimens.

\section{Transverse Reinforcement Forces}

Strain gauges were installed on the transverse bars of the test specimens in order to derive axial and bending forces in the plane of load application. The bar forces discussed below were measured at the midpoint of the $\mathrm{T}$ and T' transverse bars (see Figure 2) at the cross-over with the central headed bar. A strain gauge was also installed on the shear stud where it crossed the headed bars. Axial forces and bending moments were derived from the measured strains assuming plane sections remained plane. Stresses were calculated for an idealised elastic-plastic stress-strain curve since the reinforcement had a well-defined yield plateau and measured strains did not approach the strain hardening region. A similar approach was used to calculate forces in the bars of the finite element model.

Figures 10 and 11 show that trends in the development of axial force, $N_{t r}$, and bending moment, $M_{t r}$, in the transverse bars are well captured by the NLFEA but with some scatter. Internal forces in the T' bar are initially underestimated but good agreement is obtained with the experimental forces at later loading stages. Internal forces in the less stressed T bar are somewhat underestimated throughout the analysis but this is not significant for design if the same bar size is used for the T and T' bars. Inaccuracies in the predicted forces probably arise from simplifications made in the numerical model. For example, the assumption of perfect bond and the modelling of bar cross sections as square may have affected the engagement of the transverse bars with the main bar heads. Axial forces in the shear studs, $\mathrm{N}_{\mathrm{s}}$, are very well simulated in the NLFEA (Figure 12). 


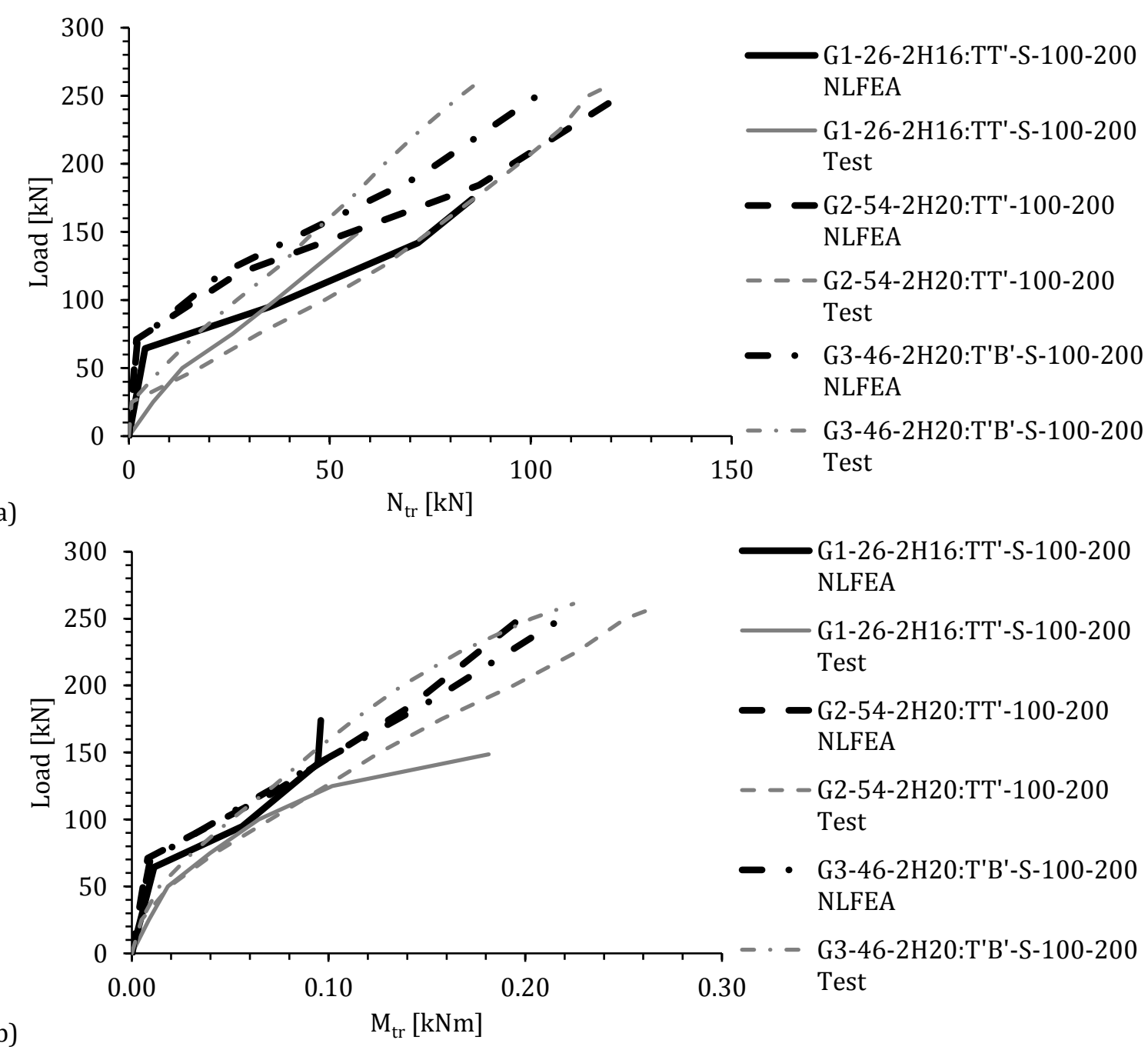

Figure 10: Transverse reinforcement forces in $T^{\prime}$ bar a) axial force and b) bending moment 


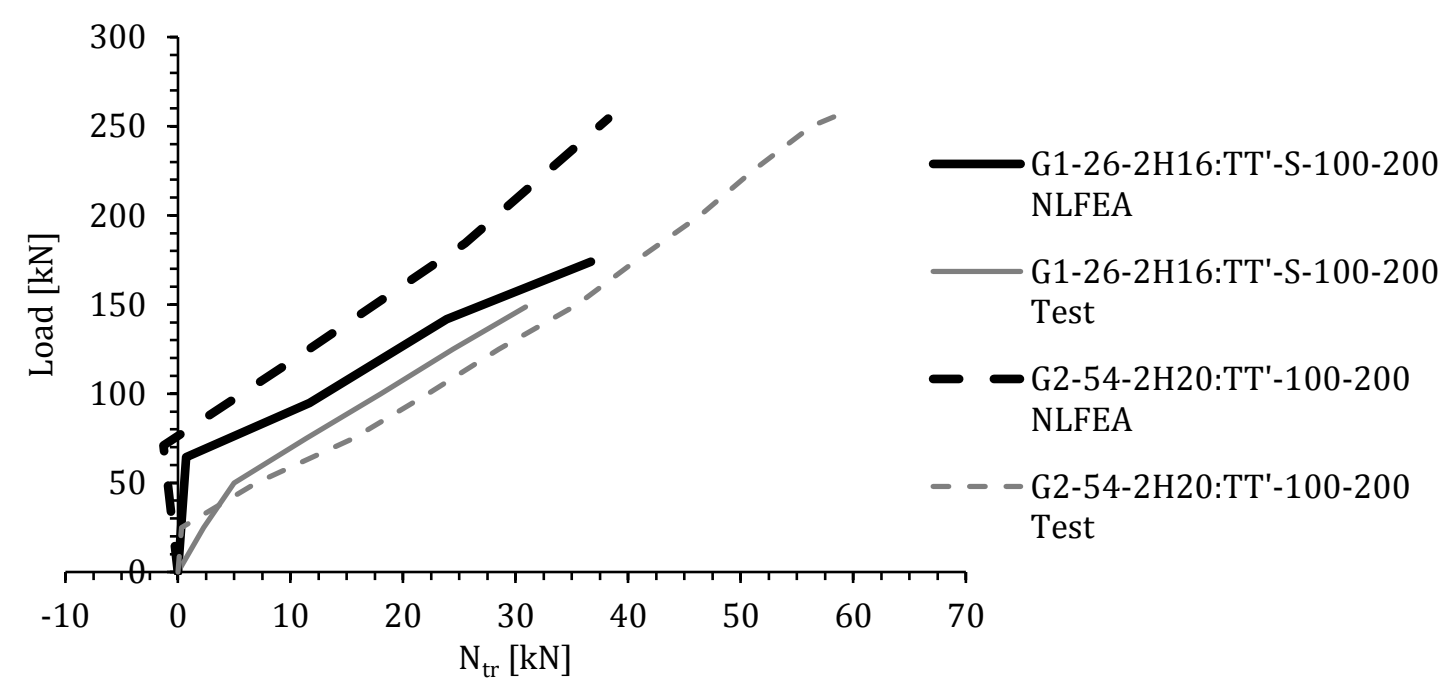

(a)

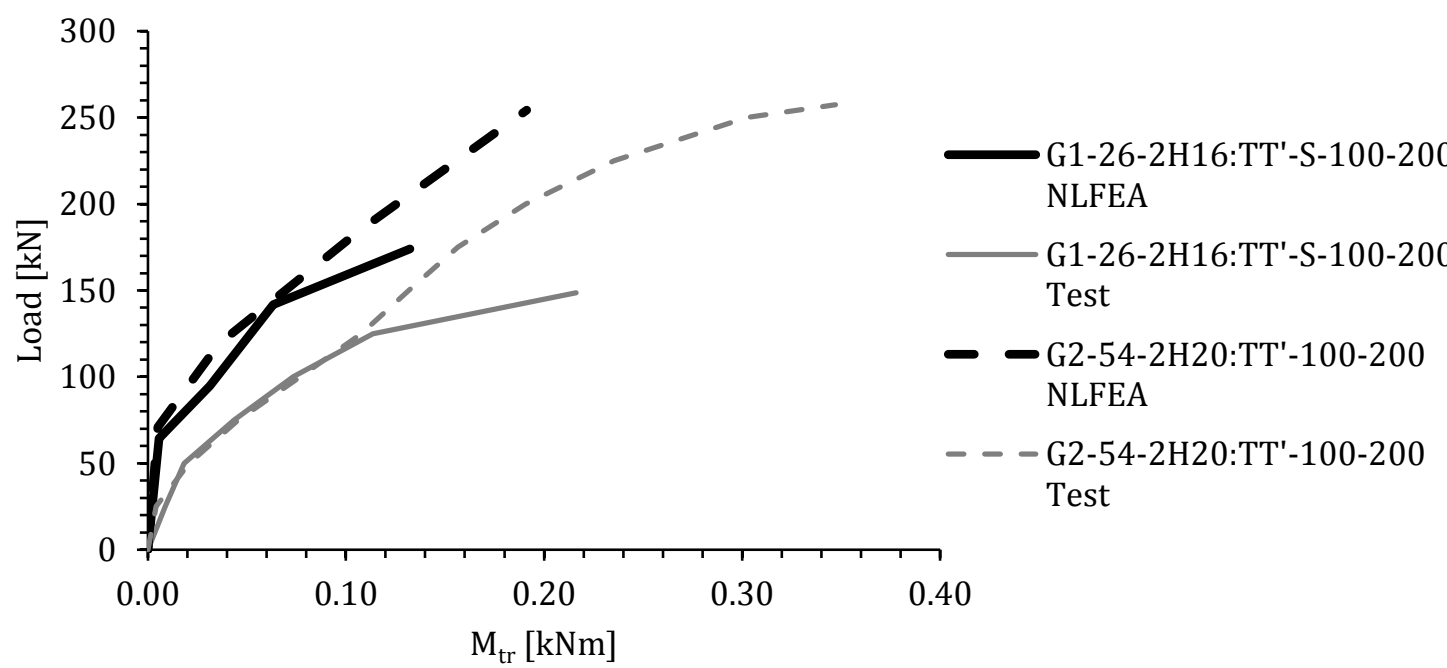

Figure 11: Transverse reinforcement forces in $T$ bar a) axial force and b) bending moment

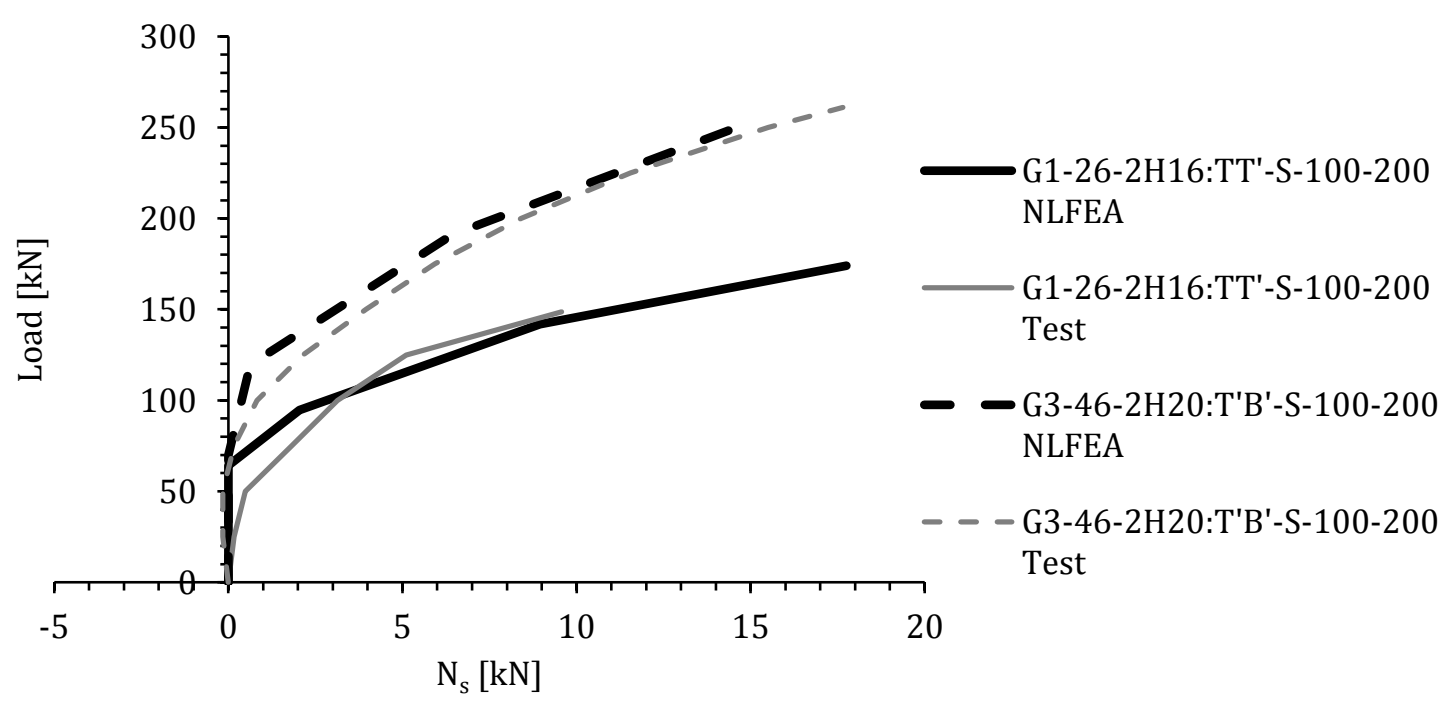

Figure 12: Axial force in shear stud 


\section{Parametric Studies}

The previous section shows that the NLFEA captures the observed behaviour of the tested specimens adequately. The validated NLFEA model was used to study the influence on joint strength of variables not fully investigated experimentally. In each case, the numerical results are compared to at least one relevant test.

\section{Lap length and spacing of headed bars}
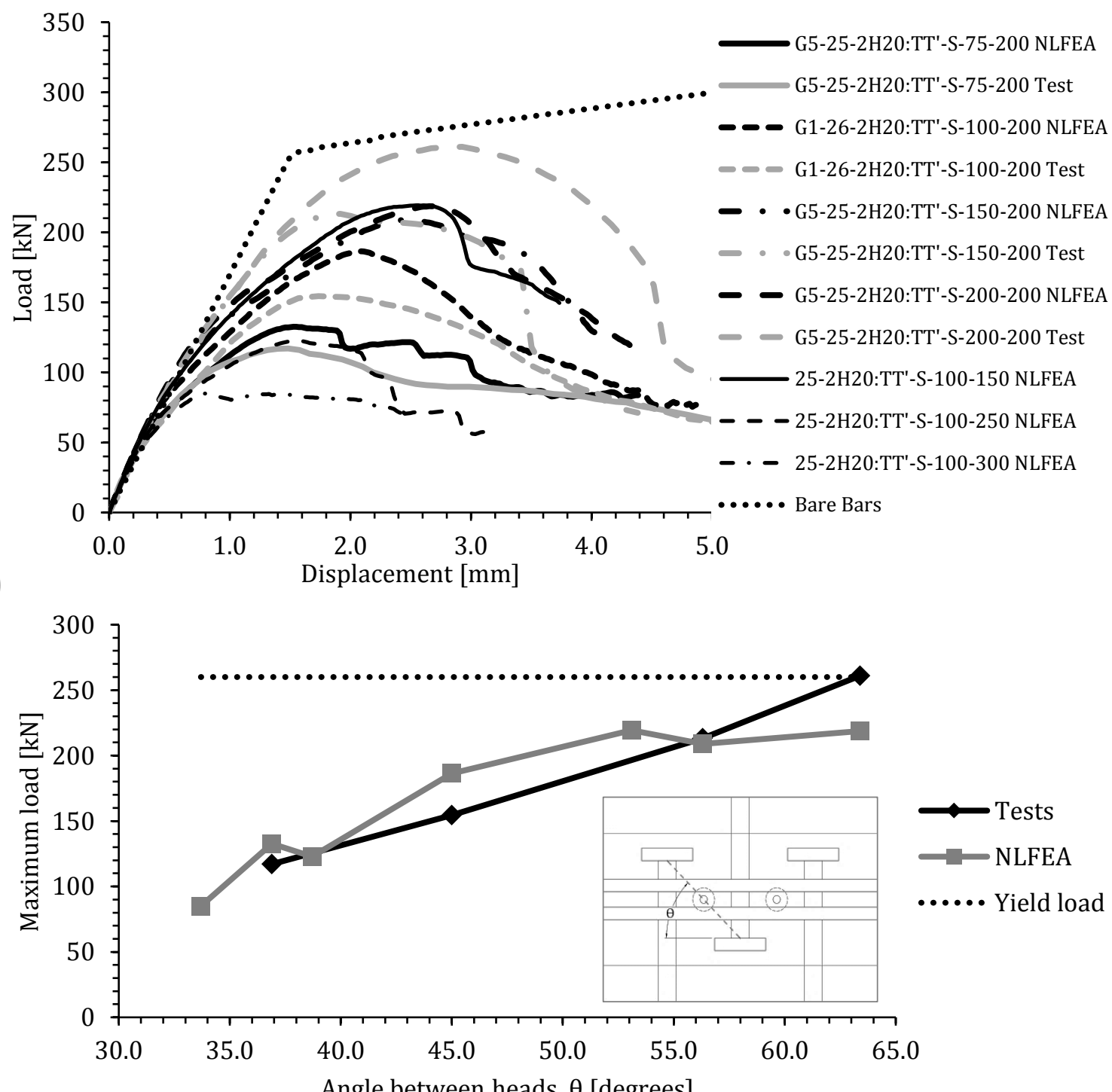

(b)

Figure 13: Effect of lap length and spacing of headed bars a) load displacement response and b) influence of angle, $\theta$

The short lap length adopted in the authors' tests allows a very efficient construction process due to the maximisation of precast element area. Most of the tests adopted a $100 \mathrm{~mm}$ lap length and $200 \mathrm{~mm}$ headed bar spacing which is standard for the E6 joint. Test groups 4 and 5 (see Table 1) studied the influence of 
varying the headed bar spacing and lap length respectively. However, these two groups are not directly comparable due to the different concrete strengths used. The tests in group 5 were taken as a reference in this study and the group 4 specimens were analysed with the group 5 concrete strength of $24.8 \mathrm{MPa}$. The reference concrete strength was chosen as $24.8 \mathrm{MPa}$ because the group 5 specimens with laps of $150 \mathrm{~mm}$ and $200 \mathrm{~mm}$ would have failed due to headed bar yield if analysed with the group 4 concrete strength of 39.2 MPa. Figure 13a shows that the FEM gives reasonable predictions of the measured load displacement responses of the G1 and G5 specimens with 2H20 TT' transverse bars, shear studs and concrete strength around $25 \mathrm{MPa}$. All specimens had a rather ductile post-peak response as a result of the low concrete strength considered. Figure 13b shows the influence on measured and predicted joint strength of the inclination $\theta$, to the transverse reinforcement, of a diagonal line drawn between adjacent bar heads. As well as including all the specimens in Figure 13a, Figure 13b includes predicted strengths for the three specimens in G4 calculated with a concrete strength of $24.8 \mathrm{MPa}$. The measured joint strengths vary almost linearly with $\theta$. The NLFEA broadly captures the influence of $\theta$ apart from the beneficial effect of increasing $\theta$ beyond 55 degrees. Consideration of Figure 13a shows that the measured and predicted joint stiffness also increase with increasing $\theta$.

\section{Transverse bar arrangement}

The test results show that changing the spatial arrangement of transverse bars has a significant effect on joint performance. Figure 14 compares the measured and predicted load displacement response of specimens G1-26-2H16:TT'-S-100-200 and G1-28-4H16:TT'BB'-S-100-200, which had similar concrete strengths. Additionally, Figure 14 shows predicted responses for other transverse bar arrangements (see Figure 2). The NLFEA captures the observed behaviour of the tested specimens reasonably well but slightly over- or under-estimates the observed failure loads. The lowest calculated joint strength is achieved when the transverse bars are placed in the B and B' positions (see Figure 2) for which the STM of Figure 3 gives equal resistance to specimens with TT" bars. Similar calculated peak loads are achieved when bars are placed in either the TT' or TB positions but a more ductile post-peak response is obtained for the TB position due to the transverse bars being positioned symmetrically with respect to the headed bars. The STM of Figure 3 gives zero resistance for specimens with only TB bars. Moving the transverse bars from the TT' to T'B' positions increases resistance by $15 \%$, as well as stiffness, but the post peak response is more brittle. The greatest observed and predicted joint strength, stiffness and ductility are 
achieved with four transverse bars. This is not captured by the STM in Figure 3 in which only the T' and B' bars are effective and no distinction is made between T' and B' bars.

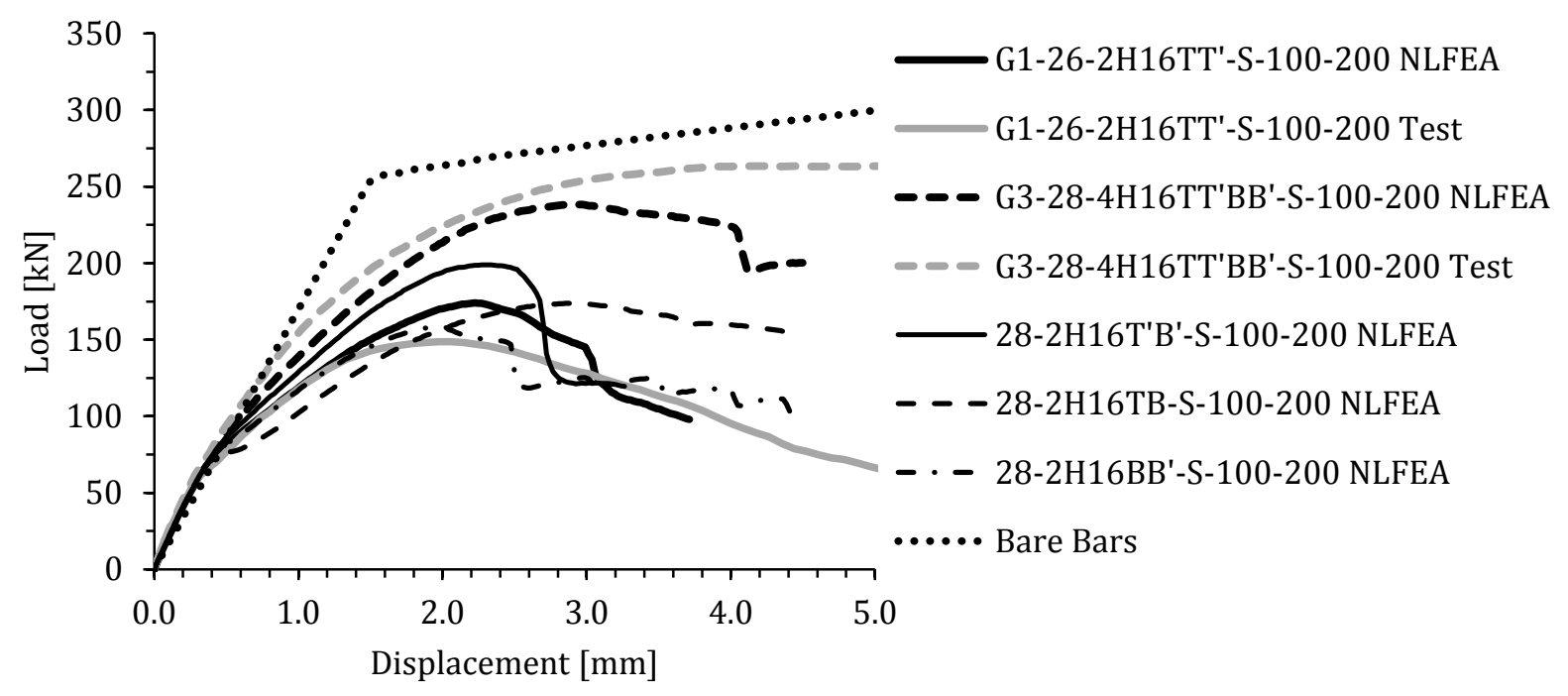

Figure 14: Effect of transverse bar arrangement

\section{Shear stud size}

Comparison of the strengths of corresponding specimens from groups 1 and 2 in Table 1 shows that shear studs increase joint strength. Figure 15a shows that adding shear studs to specimen G2-40-2H16:TT'100-200 increases the measured and calculated joint strengths by $28 \%$ and $11 \%$ respectively. The effect of increasing the shear stud diameter, whilst keeping the head size at three times the stud diameter, was investigated with NLFEA and found to have no significant effect on joint strength. However, the axial force in the shear stud increased with stud diameter (see Figure 15b) suggesting that the NLFEA may not fully capture the confining effect of shear studs. However, it should be noted that the measured and calculated stress in the shear studs at joint failure was at most around $50 \%$ of yield. This has implications for the calculation of concrete strength in the diagonal struts of the STM in Figure 3 (Vella et al., 2017a) since shear studs are assumed to provide out of plane confinement. Currently, the confining stress is calculated in the STM assuming shear studs yield at failure (Vella et al., 2017a) which is unrealistic. However, it should be noted that even with the assumption of shear stud yield the STM provides a lower bound estimate of joint strength in the authors' tension and flexural tests (Vella et al., 2017a, b) with shear stud diameters of $10 \mathrm{~mm}$ and $12 \mathrm{~mm}$ respectively. The shear studs were positioned as shown in Figure 1 in the flexural tests, which were on $300 \mathrm{~mm}$ thick slabs. 


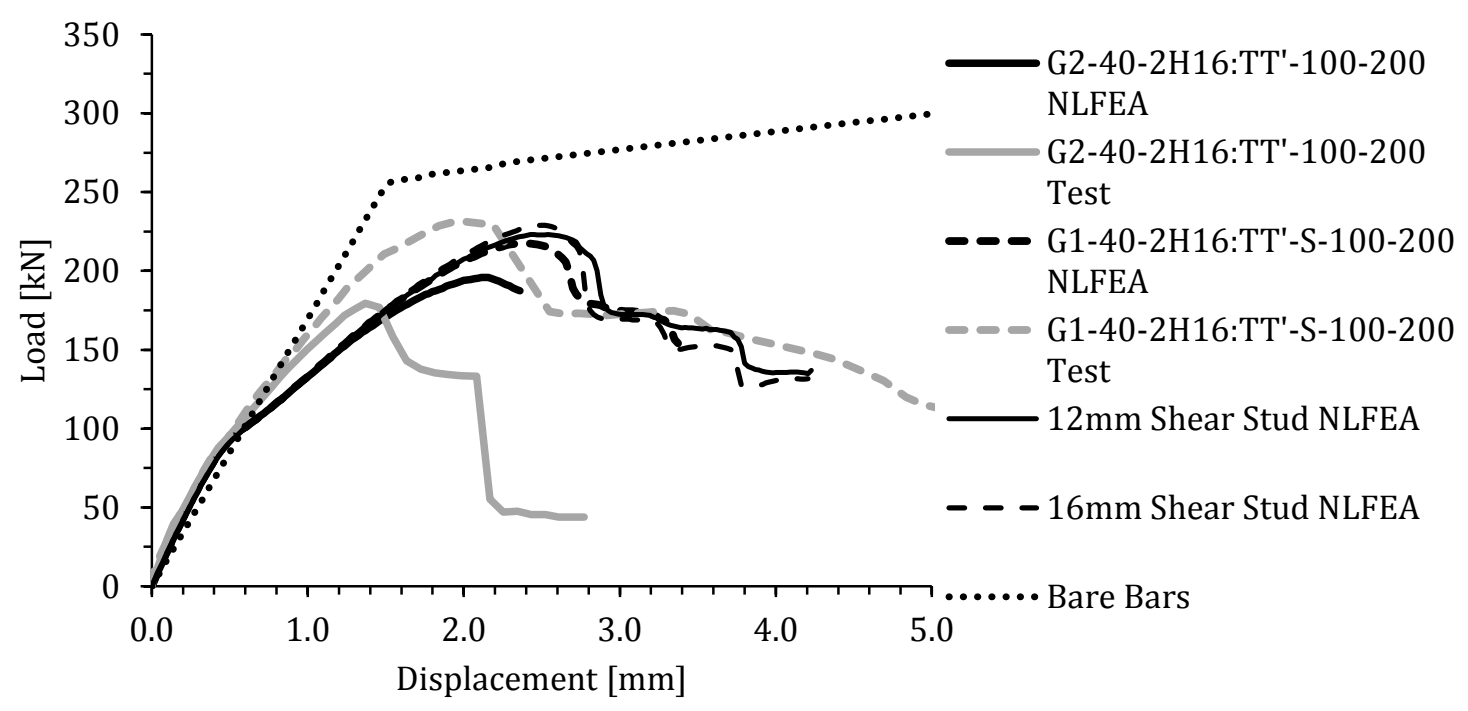

(a)

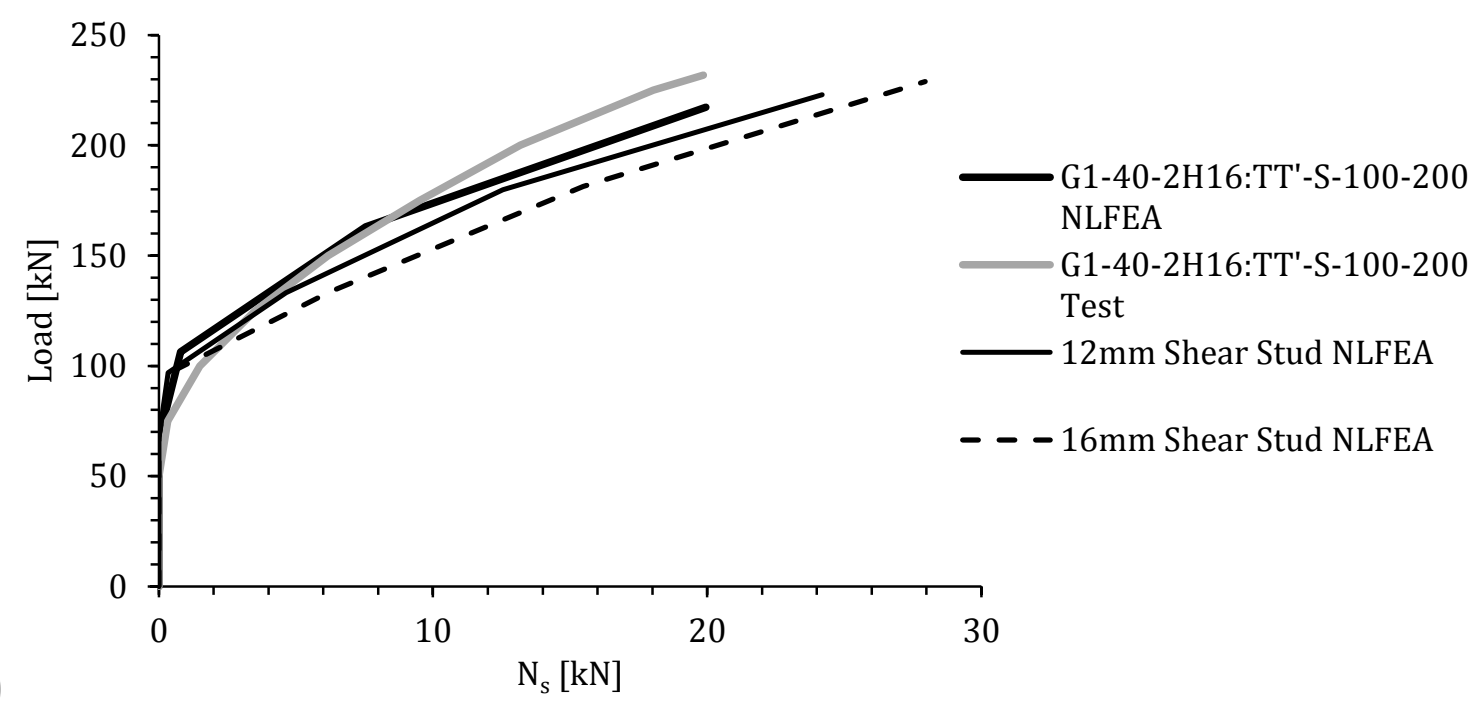

Figure 15: Effect of shear stud size a) Load displacement and b) axial load in shear stud

Headed bar axis distance

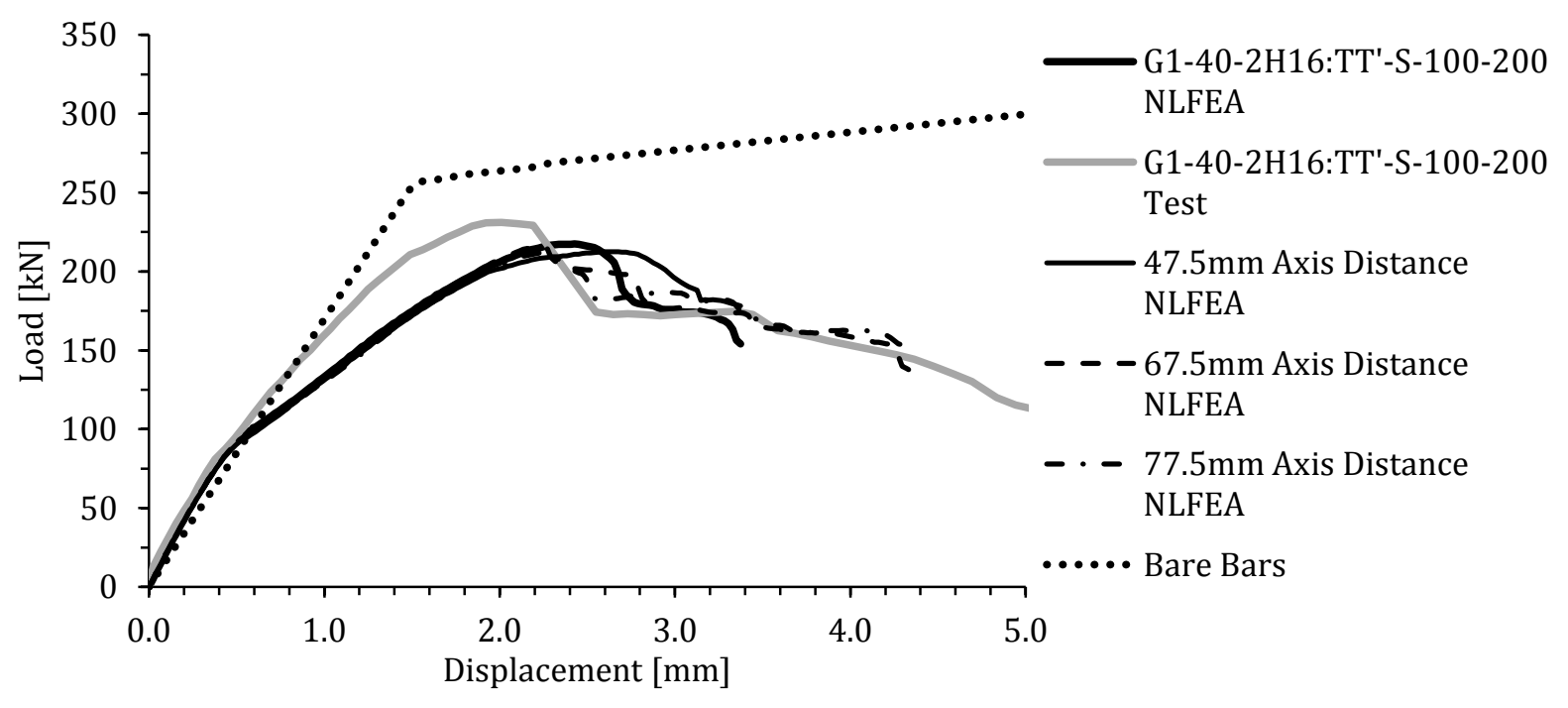

Figure 16: Effect of headed bar axis distance 
The minimum cover to the headed bars was $45 \mathrm{~mm}$ in all the tested specimens. In practice, cover varies due to construction tolerances and durability requirements. Therefore, the effect of varying the cover to the headed bars was investigated numerically for specimen G1-40-2H16:TT'-S-100-200. The results are shown in Figure 16 where the headed bar position is defined in terms of its axis distance which equals the cover plus $12.5 \mathrm{~mm}$. Figure 16 shows that the axis distance has minimal influence on the predicted loaddisplacement response.

\section{Vertical offset of headed bars}

In design, it is necessary to consider the effect of headed bars being placed out of position due to construction tolerances. This was investigated numerically by displacing the loaded and transverse bars upwards in the z direction, as defined in Figure 4, leaving the supporting bar in its original position. Preliminary analysis showed that the loading eccentricity caused the specimen to rotate significantly. In practice, this rotation is restrained by the adjacent precast slabs. Therefore, additional restraints were applied in the z-direction (see Figure 4) to the headed bars where not embedded in concrete. Figure 17 shows that a $5 \mathrm{~mm}$ offset had negligible effect on joint performance, while a $10 \mathrm{~mm}$ offset resulted in a $5 \%$ reduction in strength with no influence on joint stiffness. The $5 \%$ reduction in strength is comparable to the $10 \%$ reduction in bending resistance observed for the same offset (Vella et al., 2017b) in a flexural test of the joint configuration shown in Figure 1. Further research is required to fully determine the influence of construction tolerances on joint strength but the effect seems relatively small.

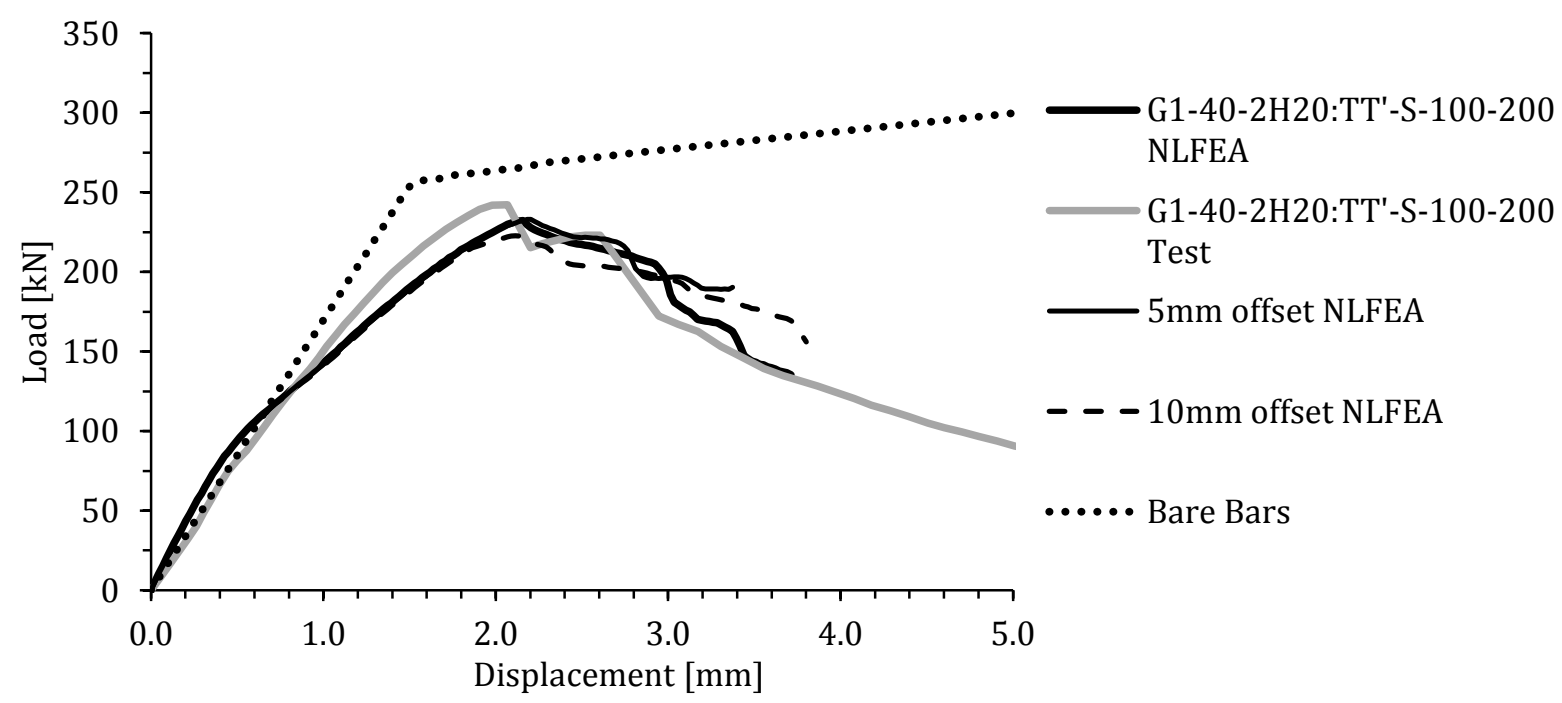

Figure 17: Effect of out-of-plane offset of headed bars 


\section{Design implications}

The validation studies show that the NLFEA simulates the response of the tested specimens well.

Additionally, the parametric studies show the usefulness of the NLFEM in investigating the influence of parameters not considered experimentally. Significantly, the NLFEA predicts axial stresses in the shear studs to not exceed $50 \%$ of yield and joint strength to be relatively insensitive to vertical construction tolerances of $10 \mathrm{~mm}$. The selected comparisons with test data suggest that the parametric predictions are credible. For standard joint geometries, it is suggested that design can reasonably be based on NLFEA simulations, validated by limited testing, provided that allowance is made for construction tolerances and a suitable safety format is adopted such as the Global Resistance Factor method of fib MC2010 (fib, 2013 ).

\section{Conclusions}

The paper describes a series of tensile tests carried out to simulate the tensile zone of an in-situ joint between precast flooring units loaded in flexure. The tests investigated the influence of joint geometry, concrete strength, transverse reinforcement and shear studs on joint strength. The test results were used to calibrate a numerical model developed in the software ATENA-GiD. The numerical model is shown to capture joint behaviour reasonably well and is considered suitable for the design of standard joint configurations provided a suitable safety format is adopted. Additionally, the FEM can assist the development of design oriented analysis methods. Further parametric studies were carried out to investigate variables not fully considered in the laboratory tests including joint geometry, transverse reinforcement arrangement, shear stud size, cover and relative out-of-plane offset of the headed bars. The key observations from the NLFEA are:

a) Safe strength predictions are obtained for joints failing near or above the yield strength of the headed bars which are of most interest in practice

b) Joint strength increases with increasing inclination $\theta$, to the transverse reinforcement, of a diagonal line drawn between adjacent bar heads

c) Placing transverse bars in two layers above and below the main headed bars increases joint strength and stiffness compared with bars placing transverse bars in only one layer.

d) Increasing the shear stud diameter above $10 \mathrm{~mm}$ only marginally increases calculated joint capacity. Furthermore, shear studs reach at maximum $50 \%$ of yield stress. 
e) Out-of-plane offsets between the headed bars of up to $10 \mathrm{~mm}$ and variations in cover did not affect the calculated joint performance significantly

It is hoped that the understanding of joint behaviour gained in this research will promote the use of headed bar tension splices in precast concrete construction.

\section{Acknowledgements}

This research project is funded by Laing O’Rourke.

\section{References}

Benes S, Mikolaskova J \& Altman T (2015) ATENA program documentation, Part 12: User's manual for ATENA studio. Prague: Cervenka Consulting.

Cervenka V, Cervenka J, Janda Z and Pryl D (2014) ATENA program documentation, Part 8: User's manual for ATENA-GiD interface. February 2014 ed. Prague: Cervenka Consulting.

Cervenka V, Jendele L and Cervenka J (2013) ATENA program documentation, Part 1: Theory. Prague: Cervenka Consulting.

Chun S (2015) Lap splice tests using high-strength headed bars of $550 \mathrm{MPa}$ (80 ksi) yield strength. $A C I$ Structural Journal, 112(6): 679 - 688.

Costa R, Providencia P and Dias A (2015) Considering the size and strength of beam-column joints in the design of RC frames. Structural Concrete, 16(2): 233 - 248.

Ferreira MP, Melo GS, Regan PE, and Vollum RL (2014) Punching of RC flat slabs with double headed shear reinforcement, ACI Structural Journal, 2014, 111(2): 363-74

fib (Fédération International du Béton) (1999) Structural concrete. Textbook on behaviour, design and performance Volume 1.

fib (Fédération International du Béton) (2013) fib Model Code for concrete structures 2010. Fédération International du Béton, Lausanne, Switzerland.

Hegger J, Sherif A and Roeser W (2004) Nonlinear finite element analysis of reinforced concrete beamcolumn connections. ACI Structural Journal, 101(5): 604 - 614. 
Hendriks MAN, Uijl JAD, Boer AD, Feenstra PH, Belletti B and Damoni C (2012) Guidelines for nonlinear finite element analysis of concrete structures. Rijkswaterstaat Centre for Infrastructure.

Li L, Ma Z, Griffey ME and Oesterle RG (2010a) Improved longitudinal joint details in decked bulb tees for accelerated bridge construction: Concept development. Journal of Bridge Engineering, 15(3): 327 - 336.

Li L, Ma Z and Oesterle RG (2010b) Improved longitudinal joint details in decked bulb tees for accelerated bridge construction: Fatigue evaluation. Journal of Bridge Engineering, 15(5): 511 - 522.

Menetrey $\mathrm{P}$ and Willam KJ (1995) Triaxial failure criterion for concrete and its generalization. $A C I$ Structural Journal, 92(3): 311 - 318.

Pryl D and Cervenka J (2014) ATENA program documentation, Part 11: Troubleshooting manual. Prague: Cervenka Consulting.

Thompson MK, Ledesma A, Jirsa JO and Breen JE (2006) Lap splices anchored by headed bars. ACI Structural Journal, 103(2): 271 - 279.

Thompson, MK, Ledesma, AL, Jirsa JO, Breen JE and Klingner RE (2003) Anchorage behaviour of headed reinforcement. The University of Texas at Austin.

Van Mier JGM (1986) Multiaxial strain-softening of concrete. Materials and Structures, 19(111): 179 190.

Vecchio FJ and Collins MP (1986) The modified compression-field theory for reinforced concrete elements subjected to shear. ACI Journal, 83(2): 219 - 231.

Vella JP, Vollum RL and Jackson A (2017a) Investigation of headed bar joints between precast concrete panels. Engineering Structures, 138C: 351 - 366.

Vella JP, Vollum RL and Jackson A (2017b) Headed bar connections between precast concrete panels loaded in bending. fib (Fédération International du Béton) Symposium 2017 High-tech Concrete: Where Technology and Engineering Meet! Maastricht, The Netherlands: fib (Fédération International du Béton). 